\title{
Warm Conveyor Belts and Their Role for Cloud Radiative Forcing in the Extratropical Storm Tracks
}

\author{
HANNA JOOS \\ Institute for Atmospheric and Climate Science, ETH Zurich, Zurich, Switzerland
}

(Manuscript received 23 November 2018, in final form 28 May 2019)

\begin{abstract}
The link between cloud radiative forcing (CRF) and warm conveyor belts (WCBs), which are strongly ascending airstreams in extratropical cyclones, is investigated based on ERA-Interim reanalysis from 1979 to 2011. Clouds associated with WCBs can be liquid, mixed phase, or ice clouds. They interact with the longwave and shortwave radiation in different ways and thus strongly influence Earth's radiative budget in the extratropical storm tracks in a complex way. In this study, WCBs are identified with a Lagrangian method, where WCBs are represented by trajectories that rise at least $600 \mathrm{hPa}$ in $48 \mathrm{~h}$ in the vicinity of an extratropical cyclone, and CRF is traced along all WCB trajectories during the considered 30 -yr period. The results show that due to the poleward ascent of WCBs, they exhibit negative net cloud forcing (NetCRF) in the southern part of the associated cloud band, whereas in their northern part, NetCRF gets positive due to the lack of sunlight in the winter months. This nonuniform CRF along WCBs from low to high latitudes increases the meridional NetCRF gradient. Furthermore, in their outflow regions in the North Atlantic, where WCBs are mainly associated with ice clouds, WCBs contribute up to $10 \mathrm{~W} \mathrm{~m}^{-2}$ to the global climatological NetCRF maximum in winter. The results highlight the importance of WCBs in modulating the radiative budget in the extratropics. Furthermore, the results emphasize the need for a correct representation of WCBs in climate models to correctly simulate the cloud-circulation coupling.
\end{abstract}

\section{Introduction}

Clouds are important for Earth's radiative budget. The formation of clouds is driven by different (large scale) circulation patterns like the intertropical convergence zone with deep convection in the tropics, marine boundary layer clouds formed in subsidence regions in the subtropics, and clouds related to extratropical cyclones in the midlatitude storm tracks. Depending on their altitude and microphysical properties, clouds can have a warming (greenhouse) or cooling (albedo) effect on the Earth-atmosphere system (Ramanathan et al. 1989; Klein and Hartmann 1993). Typically, in deep convective clouds, the greenhouse and albedo effects nearly cancel each other leading to a small net cloud forcing. Marine stratocumulus clouds lead to a strong cooling due to their high reflectivity, low altitude, and occurrence over the dark ocean surface. In contrast, high ice clouds with cold cloud tops exert a warming effect as they trap outgoing longwave radiation while being mostly transparent for incoming shortwave radiation

\footnotetext{
Corresponding author: Hanna Joos, hanna.joos@env.ethz.ch
}

(e.g., Boucher et al. 2013). Clouds associated with the midlatitude storm tracks can consist of low-level liquid, mixed phase, and high-level cirrus clouds with strongly differing effects on radiation. The net effect, thus the climatology of cloud radiative forcing (CRF) in the midlatitudes is strongly influenced by individual synoptic weather systems and their associated cloud bands, which exhibit a pronounced day-to-day variability. To better understand the climatological signal in the extratropical storm track it is therefore necessary to first understand the contribution of individual weather systems, like extratropical cyclones, to CRF.

The importance of extratropical cyclones for CRF has been investigated in several studies. Wylie and Menzel (1989) and Stewart et al. (1998) stated that due to their enhanced cloud water path and the association with high-level ice clouds, extratropical cyclones have a strong impact on CRF. Tselioudis and Rossow (2006) showed that there is a clear relationship between midlatitude storm intensity and cloudiness such that more intense storms produce more clouds and larger shortwave and longwave cloud forcing. Govekar et al. (2011) evaluated the distribution of CRF based on satellite data 

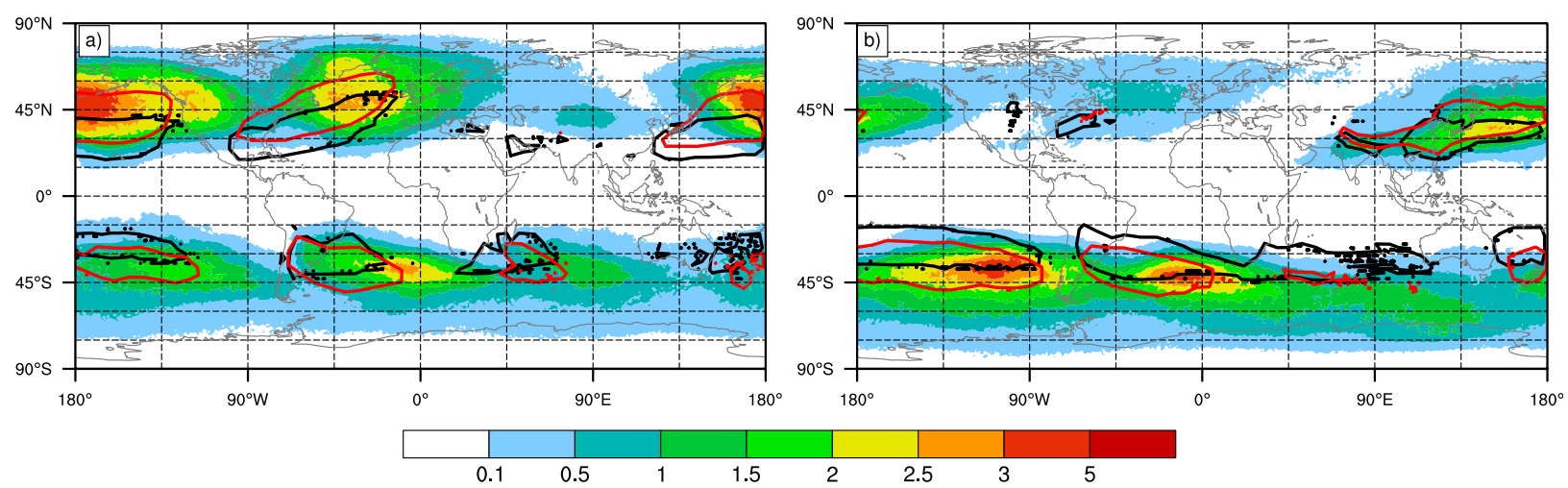

FIG. 1. Climatological frequency of WCB trajectories for (a) DJF and (b) JJA. Colors denote the percentage of 6-hourly time steps during which at least one WCB trajectory is located somewhere in the vertical column of the considered grid point. Here, colors show the percentage of WCB trajectories at the end of their ascent at $t=48 \mathrm{~h}$. Black lines show a frequency of $1 \%$ for WCBs at $t=0 \mathrm{~h}$ (WCB start points), and red lines the frequency of $1 \%$ for WCBs at $t=24 \mathrm{~h}$.

in cyclone composites and showed that the longwave cloud forcing is highest over the warm front where also most of the high cirrus clouds occur. A study by McCoy et al. (2018), which is also based on satellite data, showed that stronger moisture inflows enhance the liquid water path in cyclones and thus their shortwave cloud forcing.

CRF in extratropical cyclones is produced by a variety of clouds that occur at different heights and exhibit different microphysical properties. The main cloudproducing airstreams in extratropical cyclones, and thus likely the most essential flow features for CRF, are so-called warm conveyor belts (WCBs). WCBs are strongly rising airstreams that ascend in $\sim 2$ days from the boundary layer of the cyclone's warm sector to the upper troposphere and are therefore the main cloud and precipitation producing airstreams in extratropical cyclones (Browning 1986; Pfahl et al. 2014). The elongated cloud band ahead of the cold front as well as the widespread cirrus shield northeast of the cyclone center is often linked to the WCB. Due to its high reflectivity the WCB cloud band can be nicely seen in satellite pictures (see Fig. 2b).

Madonna et al. (2014) compiled a global climatology of WCBs based on the ERA-Interim reanalysis dataset covering the time period from 1979 to 2011 . Trajectories are started every $6 \mathrm{~h}$ during the whole time period. In the horizontal they are started every $80 \mathrm{~km}$ and vertically, between 1050 and $790 \mathrm{hPa}$ in the atmospheric boundary layer. The trajectories are calculated $48 \mathrm{~h}$ forward in time based on the ERA-Interim 3D wind field. All trajectories that ascend at least $600 \mathrm{hPa}$ in these $48 \mathrm{~h}$ in the vicinity of an extratropical cyclone are selected as WCB trajectories. A more detailed description of the calculation of WCBs is given in section 2. In Fig. 1, this climatology is shown for December-February (DJF) and June-August (JJA), separately. The colors and lines denote the frequency of occurrence of WCBs at each grid point at different time steps during their ascent. In the Northern Hemisphere, WCB starting positions are located mainly in the western North Atlantic and North Pacific (black lines) located to the south of the winter storm-track entrance region and travel poleward and eastward during their $48 \mathrm{~h}$ ascent. In the Southern Hemisphere, WCB starting regions are fairly equally distributed in the zonal direction with a maximum over South America and a minimum over Australia also in good agreement with the cyclone climatology (Wernli and Schwierz 2006). The occurrence of WCBs shows a pronounced seasonal cycle with higher frequencies of occurrence during the winter months as the associated cyclones are also more frequent during winter. For more detailed information about the calculation of WCBs, their climatology, and relevance, please refer to Madonna et al. (2014).

As clouds strongly modify longwave and shortwave radiation, a correct representation of this modification is essential for global climate models, especially with regard to future climate projections. However, the representation of clouds and their impact on radiation in climate models still leads to major uncertainties in the assessment of climate sensitivity (e.g., Boucher et al. 2013; Vial et al. 2013; Zelinka et al. 2013; Ceppi and Hartmann 2015; Bony et al. 2015; Shaw et al. 2016; Caldwell et al. 2016) and there is increasing evidence that cloud processes contribute to the spread in the dynamical response to a warmer climate (Ceppi and Hartmann 2015). Furthermore, the representation of the extratropical circulation response to climate change in current climate models is not well constrained and the associated changes in cloud patterns and their radiative impacts remain unclear (Barnes and Polvani 2013; Shepherd 2014; Bony et al. 2015; Shaw et al. 2016). 
Changes of the impact of extratropical cyclones on CRF in a warmer climate are also not fully understood. So far it could be shown that midlatitude storm tracks might shift poleward toward regions of reduced insolation (Bender et al. 2012; Grise et al. 2013; Eastman and Warren 2013), although the future position and strength of storm tracks depend on processes that alter the meridional temperature gradient (Shaw et al. 2016), like changes in the position and microphysical properties of clouds that strongly determine how much radiation reaches the surface or is emitted back to space. In addition to changes in the position of the storm track and the associated cloud patterns, changes in the clouds' microphysical properties have an impact on CRF. However, the overall radiative impact of clouds is a consequence of many interacting processes operating at large scales down to microscales (Stewart et al. 1998). Kodama et al. (2014) and Ceppi and Hartmann (2015) showed that only some of the enhancement in cloud liquid and shortwave cloud forcing can be attributed to storm intensity but that the rest seems to be unrelated to dynamical changes. Further investigations of microphysical changes showed that an increase of the liquid water path in clouds in a warmer climate is a key driver for an increase of the associated shortwave cloud forcing (Ceppi et al. 2016). In contrast, McCoy et al. (2018) stated that the majority of changes in liquid water path can be explained by changes in WCB moisture fluxes as opposed to cloud phase changes. All these examples highlight the complexity of processes and their changes that have to be taken into account for a realistic prediction of CRF in a future climate. To improve our understanding of climate change it is, however, essential to understand the radiative feedback of clouds. Therefore, one of the Grand Challenges of the World Climate Research Programme (WCRP) is to obtain a much more detailed understanding of the control mechanisms for the position, strengths, and variability of the extratropical storm track and its coupling to clouds (Bony et al. 2015).

In this study we aim to contribute to addressing this challenge by improving our understanding of the WCB, that is, of the impact of the main cloud-producing airstream, in the extratropical storm track on CRF in the current climate. More specifically, this study aims at quantifying (i) total condensate and CRF linked to individual cyclones and their associated cloud bands, (ii) CRF along WCB trajectories in summer and winter seasons, and (iii) the contribution of WCBs to the climatological signal of CRF in the extratropical storm tracks in summer and winter.

After introducing the data and methods in section 2, we first present a detailed case study of a WCB in the North
Atlantic and its associated cloud formation and CRF in section 3. Climatological results are presented in section 4, and a summary and discussion are provided in section 5 .

\section{Data}

To investigate the link between CRF and WCBs, we use the ERA-Interim dataset (Dee et al. 2011) covering the time period from 1979 to 2011, interpolated to a $1^{\circ} \times 1^{\circ}$ longitude-latitude grid with a time resolution of $6 \mathrm{~h}$. As indicators for clouds we use the vertically integrated total liquid water (TLW) and total ice water (TIW). The impact of clouds on radiation is described with the cloud radiative forcing. Shortwave cloud radiative forcing (SWCRF) is defined as the difference between the top-of-atmosphere (TOA) shortwave radiative flux in clear-sky conditions $S_{\text {clear-sky }}$ and cloudy conditions $S_{\text {cloud }}$, thus SWCRF $=S_{\text {clear-sky }}-S_{\text {cloud }}$ (in $\mathrm{W} \mathrm{m}^{-2}$ ). The same definition holds for the longwave cloud radiative forcing (LWCRF) with LWCRF = $L_{\text {clear-sky }}-L_{\text {cloud }}$ (Klein and Hartmann 1993). The net effect of clouds on Earth's radiative budget is then given by the net cloud radiative forcing (NetCRF), which can be calculated as NetCRF $=$ SWCRF + LWCRF.

SWCRF is negative as clouds are in general more reflective than the underlying darker surface, thus $S_{\text {cloud }}$ is larger than the corresponding clear-sky value. LWCRF is positive as more radiation is trapped in the atmosphere when clouds are present such that $L_{\text {cloud }}$ is smaller than the corresponding clear-sky value. This effect is largest for high, cold clouds as they radiate back to space with colder temperatures than the underlying surface. SWCRF, LWCRF and NetCRF are accumulated variables, thus their values represent the mean CRF that occurred during the $6 \mathrm{~h}$ before the output time step. CRF at a certain time step has been influenced by the cloud properties between the previous output time step and the actual one.

The link between cloud formation and CRF to WCBs is investigated by tracing TLW, TIW, SWCRF, LWCRF, and NetCRF along WCB trajectories. WCB trajectories have been calculated by starting $48 \mathrm{~h}$ forward trajectories horizontally every $80 \mathrm{~km}$ in a layer below $790 \mathrm{hPa}$ at every $6 \mathrm{~h}$ time step during the time period 1979 to 2011. The trajectories are calculated with the Lagrangian Analysis Tool LAGRANTO (Wernli and Davies 1997; Sprenger and Wernli 2015). All trajectories that ascend at least $600 \mathrm{hPa}$ in $48 \mathrm{~h}$ and overlap at least once during their ascent with a surface cyclone are defined as WCB trajectories. The area associated to a surface cyclone is defined as a local sea level pressure (SLP) minimum enclosed by the outermost closed SLP contour. The identification 
of cyclones is based on the method described in Wernli and Schwierz (2006). A more detailed description of the calculation of WCB trajectories can be found in Madonna et al. (2014).

It might be questioned if a reanalysis dataset should be used in order to investigate CRF. However, in several studies ERA-Interim cloud properties and cloud cover have been compared to satellite observations showing a qualitative good agreement. Stengel et al. (2018) applied a satellite simulator to the ERA-Interim dataset and compared it to satellite observations. They found that the global pattern of cloud fraction agrees very well with observations. However, ERA-Interim underestimates the cloud fraction almost everywhere on the globe, which is mainly caused by an underestimation of midlevel and low clouds, whereas the high cloud occurrence agrees within the uncertainties of the observations. Naud et al. (2014) compared the ERA-Interim cloud cover to MODIS/ MISR observations over the Southern Ocean by calculating composites over extratropical cyclones. They showed that there is a low cloud cover bias in extratropical cyclones and that the bias is largest behind the cold front where there are low-level and broken-up cloud structures like shallow cumulus. The agreement between ERA-Interim and observations is best along the warm-frontal cloud bands and at the polar edge. In a similar study, Field et al. (2011) showed composites of extratropical cyclones based on data from the Met Office Unified Model and compared them to satellite data. Although they used a different model, they also showed that there is a good qualitative agreement between observed and modeled reflectivity structures. As in our study we focus on well-defined frontal cloud bands, we therefore believe that the ERA-Interim dataset can be used in order to assess the influence of WCBs on CRF.

The results obtained with the ERA-Interim dataset have been compared to satellite data from the Clouds and the Earth's Radiant Energy System (CERES) project (Wielicki et al. 1996; CERES Science Team 2017). We use the product and dataset version CERES SYN1deg Ed4A, which provides observed TOA shortwave and longwave fluxes for clear-sky and allsky conditions with a time resolution of $3 \mathrm{~h}$ on a $1^{\circ} \times 1^{\circ}$ longitude-latitude grid. Based on these data we calculate SWCRF, LWCRF, and NetCRF as described above with a time resolution of $6 \mathrm{~h}$ in order to get the same time resolution than ERA-Interim. The CERES data are available since March 2000. To get the maximum time overlap with the ERA-Interim data we use the CERES data from January 2001 until December 2011. It has to be mentioned here that in several regions of the globe, for instance, in polar regions (north of $\sim 80^{\circ} \mathrm{N}$ and south of $\sim 70^{\circ} \mathrm{S}$ ), Greenland, northeast Africa, Siberia, the Himalayas, the Amazonas, and in parts of the western North Atlantic and Pacific at the northern edge of the storm track, valid data are available in only $1 / 3$ to maximum $2 / 3$ of the available time steps. Nevertheless, the satellite data provide valuable insight into the link between WCBs and CRF in addition to the ERA-Interim dataset.

The Lagrangian perspective with tracing variables along trajectories that describe the WCB can thus be used to investigate in detail the contribution of clouds formed within the WCB to the climatological values of CRF in the extratropics. Therefore, it provides a valuable tool to assess the link between CRF to the underlying weather systems that form the clouds. An example of a WCB and the evolution of TLW, TIW, LWCRF, SWCRF, and NetCRF along its trajectories is discussed in the next section.

\section{Case study}

The concept of WCBs and their link to TLW, TIW, and cloud radiative forcing will be explained based on a case study of a North Atlantic cyclone that occurred in January 2009. Figure 2a shows the WCB trajectories (colored lines) associated with the cyclone located south of Iceland. They represent the ascent from $>1000$ to $<400 \mathrm{hPa}$ in $48 \mathrm{~h}$ while the SLP lines are shown at a specific time (0600 UTC 30 January 2009) in the middle of the WCB ascent. It can be seen how the WCB air parcels start their strong ascent in the warm sector of the cyclone south of the cyclone center in the lower troposphere. The air parcels strongly rise mainly along the cold front, pass to the east of the cyclone center approximately $24 \mathrm{~h}$ after their start (see black points in Fig. 2a) and end in the upper troposphere over Scandinavia after their $48 \mathrm{~h}$ ascent. This coherently rising airstream is responsible for the formation of an elongated cloud band with liquid, mixed phase, and ice clouds, reaching from the African coast to Scandinavia, as can be seen in the Meteosat SEVIRI infrared satellite image (Fig. 2b). In the WCB inflow the clouds are mainly lowlevel liquid clouds with relatively warm cloud-top temperatures, whereas in the outflow region the WCB is associated with a cirrus shield with cold cloud-top temperatures (not shown). The climatological evolution of cloud species along WCBs, showing a transition from liquid to ice phase clouds via the mixed phase can be found in Madonna et al. (2014, their Figs. 7b,c). A more detailed description of the microphysics along the WCB case study presented here can be found in Joos and Wernli (2012) and Joos and Forbes (2016). Not all clouds in extratropical cyclones are associated with 


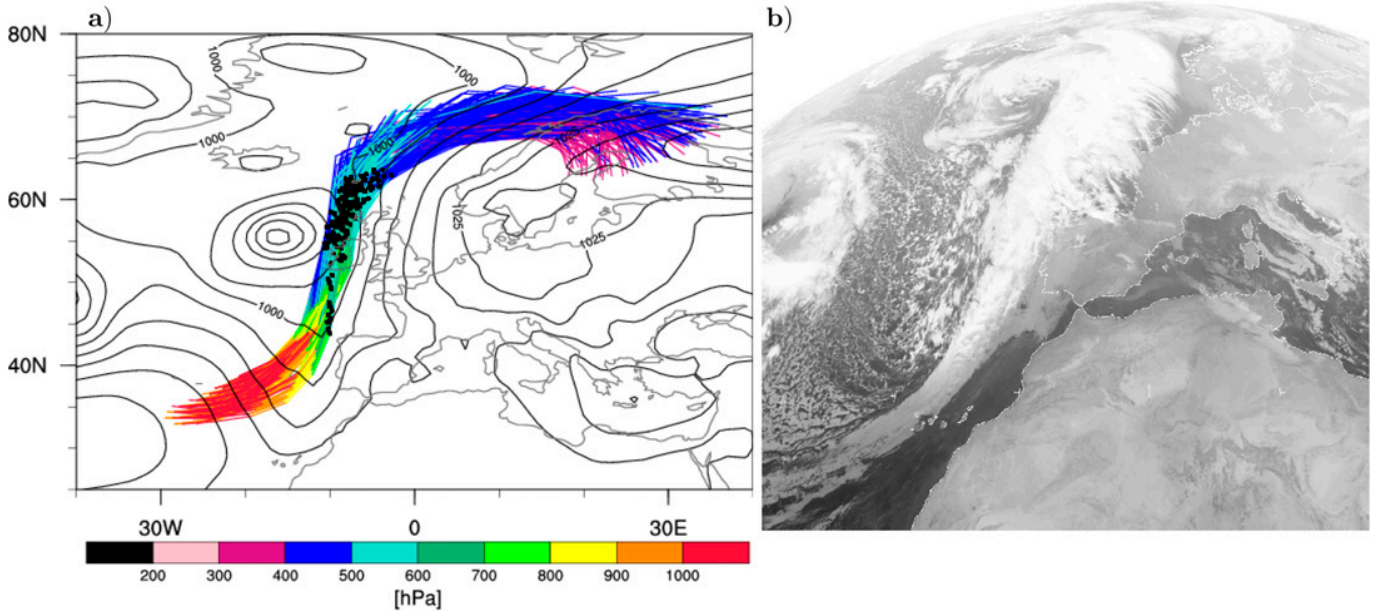

FIG. 2. (a) WCB trajectories colored with pressure for a WCB starting at 0600 UTC 29 Jan 2009. Black lines denote SLP and black dots the position of the air parcels $24 \mathrm{~h}$ after the start of the WCB at 0600 UTC 30 Jan 2009. (b) Meteosat SEVIRI infrared satellite image valid for 0600 UTC 30 Jan 2009. Figure from http:// www.neodaas.ac.uk.

WCBs. The clouds in the cyclone center as well as behind the cold front are not linked to the WCB airstream. However, due to their strong and coherent upward motion, WCBs form widespread cloud bands, which strongly interact with radiation.

The time evolution of TLW, TIW, LWCRF, SWCRF, and NetCRF along this WCB is shown in Fig. 3 as a mean over all WCB trajectories related to the presented case study based on ERA-Interim data. The evolution of CRF is additionally shown based on CERES satellite data. Time runs from $t=0$ (start of WCB ascent) to $48 \mathrm{~h}$ (end of WCB ascent). When the WCB air parcels start rising, clouds form and TLW and TIW values strongly increase and peak at about $t=12 \mathrm{~h}$. After that the values decrease due to the continuous formation of precipitation. At the end of the ascent, there is still condensate left which consists mainly of ice. However, it has to be mentioned here that TLW and TIW are two-dimensional fields. Thus, they do not represent a value at the same height as the WCB air parcel but represent a vertical integral at the horizontal position (longitude/latitude) of the WCB air parcel. It is therefore possible that the considered TLW and TIW also contain condensate that occurs below the WCB and is not associated with it (e.g., boundary layer clouds below the WCB outflow).

Associated with the increase in total condensate, LWCRF also strongly increases. As long as the WCB produces mainly low-level clouds with relatively warm cloud tops, the LWCRF in the WCB inflow is below $15 \mathrm{~W} \mathrm{~m}^{-2}$. However, as we consider the LWCRF at a later point in time along the ascent, thus at a higher altitude and a position closer to the pole, the more clouds with high and cold cloud tops form, which increases their LWCRF. After $t=30 \mathrm{~h}$, the condensate as well as LWCRF start to decrease. The SWCRF also strongly decreases (becomes more negative) when the clouds start forming during the ascent. However, as SWCRF depends on the availability of sunlight, SWCRF is zero at the starting time of the trajectories at 0600 UTC 29 January (corresponding to $t=0 \mathrm{~h}$ in Fig. 3d) as well as at 0000 and 0600 UTC 30 January $(t=$ 18 and $24 \mathrm{~h})$ and 0000 and 0600 UTC 31 January $(t=42$ and $48 \mathrm{~h}$ ) (see gray shaded areas in Figs. $3 \mathrm{~d}$ and $3 \mathrm{e}$ ). Additionally, the WCB travels far to the north during its ascent. Therefore, the SWCRF gets close to zero after $t=30 \mathrm{~h}$ due to the polar night at high latitudes in January. Finally, the resulting NetCRF shows strongly negative values during the first $12 \mathrm{~h}$ of the ascent due to the formation of a thick and highly reflective cloud band. However, when the air parcels reach high latitudes where there is no sunlight during polar night, NetCRF is dominated by LWCRF and exhibits positive values in the WCB outflow region. In addition, the evolution of LWCRF, SWCRF, and NetCRF based on CERES satellite data is shown (see black dashed lines in Figs. 3c-e). LWCRF as seen by the satellite reveals larger values as compared to ERA-Interim almost over the whole $48 \mathrm{~h}$ ascent. However the time evolution and the amplitude show a very similar behavior in both datasets. SWCRF also exhibits a very similar pattern and absolute values. The most negative values along the $\mathrm{WCB}$ are reached already after $6 \mathrm{~h}$ in the CERES data as compared to $12 \mathrm{~h}$ in ERA-Interim. Due to the larger values of LWCRF, 

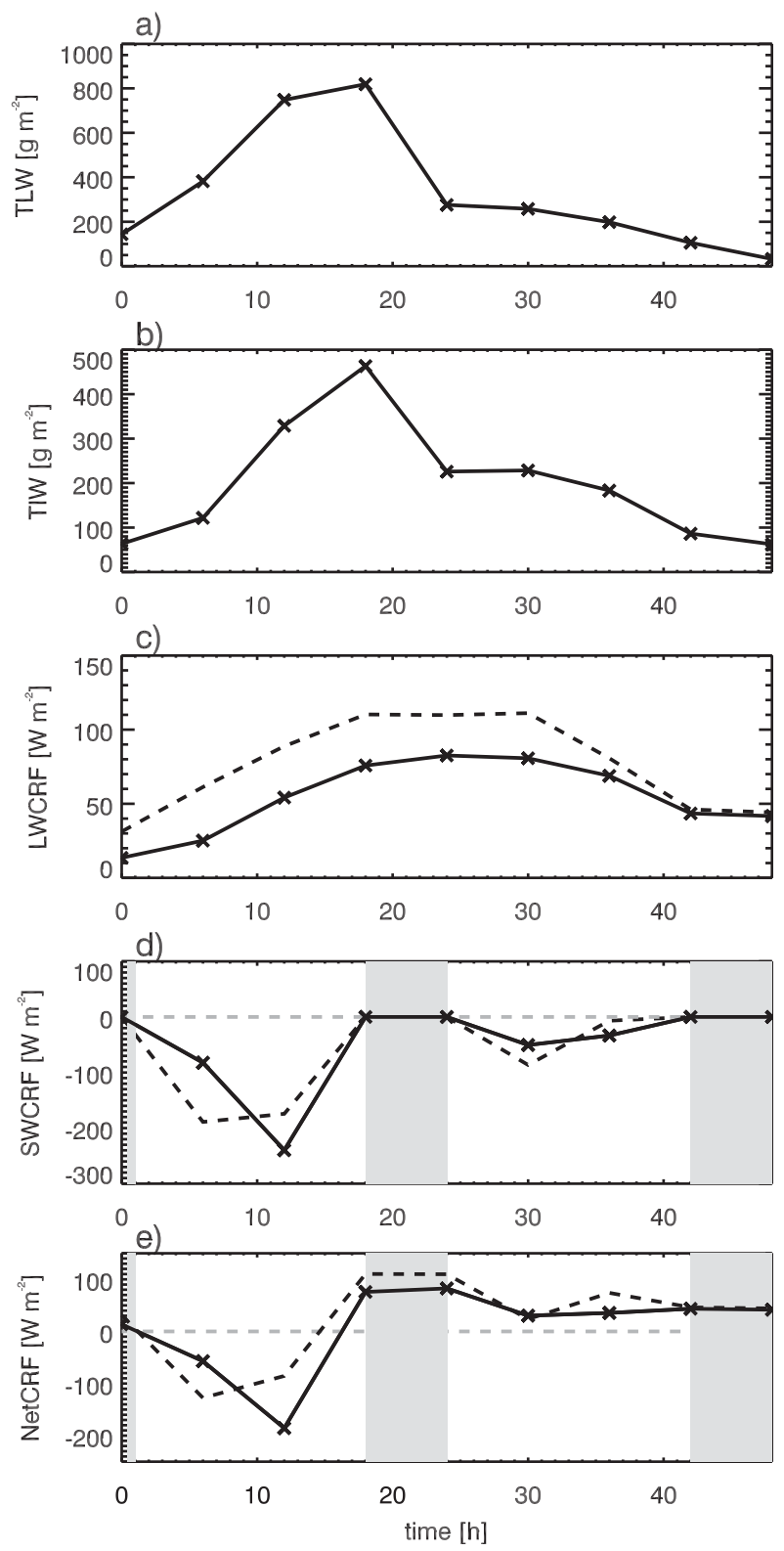

FIG. 3. (a)-(e) Time evolution of mean TLW, TIW, LWCRF, SWCRF, and NetCRF along the WCB trajectories shown in Fig. 2. The time axis denotes hours starting from 0600 UTC 29 Jan 2009 and the gray shaded areas show time instances during night (without sunlight) in the region of the WCB. In (c)-(e) the time evolution based on CERES satellite data is shown in black dashed lines. Note the different scales for TLW and TIW in (a) and (b).

the resulting NetCRF is also slightly shifted toward more positive values at the beginning of the ascent, when the NetCRF is strongly dominated by SWCRF but also at the end of the ascent when NetCRF gets positive. The resulting dipole character in NetCRF with a transition from strongly negative to positive values along the ascent is however reflected in both datasets.
The method to calculate the climatological link between WCB trajectories, total condensate, and radiative forcing is explained for the same case study with the aid of Fig. 4. In Figs. $4 \mathrm{a}$ and $4 \mathrm{~b}$ TLW and TIW in the vicinity of the North Atlantic cyclone and the position of the associated WCB air parcels are shown at 18 UTC 30 January 2009. Very high values of TLW of more than $600 \mathrm{~g} \mathrm{~m}^{-2}$ and TIW of up to $400 \mathrm{~g} \mathrm{~m}^{-2}$ occur along the cyclone's cold front, the warm front, and in the cyclone center, because in these regions the air is forced to ascend and clouds form (see Figs. 4a,b). Additionally, the position of the WCB air parcels at the same point in time (1800 UTC 30 January, black points) and $6 \mathrm{~h}$ earlier (1200 UTC 30 January, pink points) are displayed. As SWCRF, LWCRF, and NetCRF are accumulated over the last $6 \mathrm{~h}$, thus representing the time mean over the previous $6 \mathrm{~h}$, the positions of WCB air parcels at both times shown here are relevant for understanding the radiation field. We therefore consider the total condensate and cloud forcings at all grid points that are covered by black and pink (white) WCB air parcel positions to be related to this WCB. Furthermore, we only consider WCB air parcels from their inflow at $t=0 \mathrm{~h}$ to their outflow at $t=48 \mathrm{~h}$. After their $48 \mathrm{~h}$ ascent, WCB air parcels can stay for several hours or days in the upper troposphere and can still contain cloud ice, which interacts with radiation. However, for our study we use the vertically integrated TLW and TIW as indicators for clouds because the total condensate in the atmospheric column interacts with radiation. WCB air parcels spread over large and fairly shallow areas in the outflow; therefore, after $t=$ $48 \mathrm{~h}$ it becomes unlikely that the total condensate at WCB grid points can be related entirely to the WCB. Most likely, some TLW and TIW belong to clouds that form below the WCB outflow in different weather systems. Therefore, we consider only the WCB positions from $t=0-48 \mathrm{~h}$ and label all grid cells that contain WCB air parcels as WCB grid cells. In some cases this might lead to an underestimation of the TIW related to WCBs because sometimes cirrus clouds that form in the WCB and lead to a strong LWCRF exist during several days after the WCB ascent.

The SWCRF associated with the cyclone and its WCB is shown in Fig. 4c. In the region of the cold front the high TLW and TIW values produce a strongly negative SWCRF with values of less than $-180 \mathrm{Wm}^{-2}$. SWCRF strongly increases (gets less negative) toward higher latitudes. The regions of the cyclone center and the warm front to the northeast of the cyclone only exhibit weak SWCRF due to the missing sunlight despite very high TLW and TIW values. The LWCRF also shows very high values of more than $90 \mathrm{~W} \mathrm{~m}^{-2}$ in the frontal regions and the cyclone center (Fig. 4d). As LWCRF does not depend on sunlight, it shows high values everywhere where high total condensate values are found. The resulting NetCRF is shown in Fig. 4e. In the southern part of the WCB-related cloud band, SWCRF is 
(a) TLW

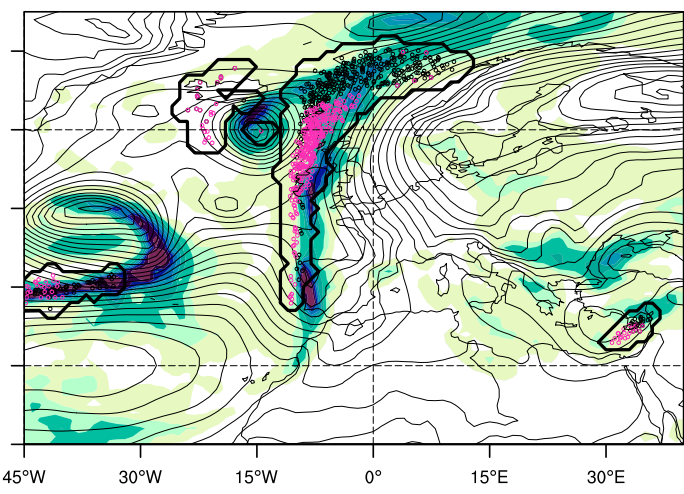

(c) SWCRF

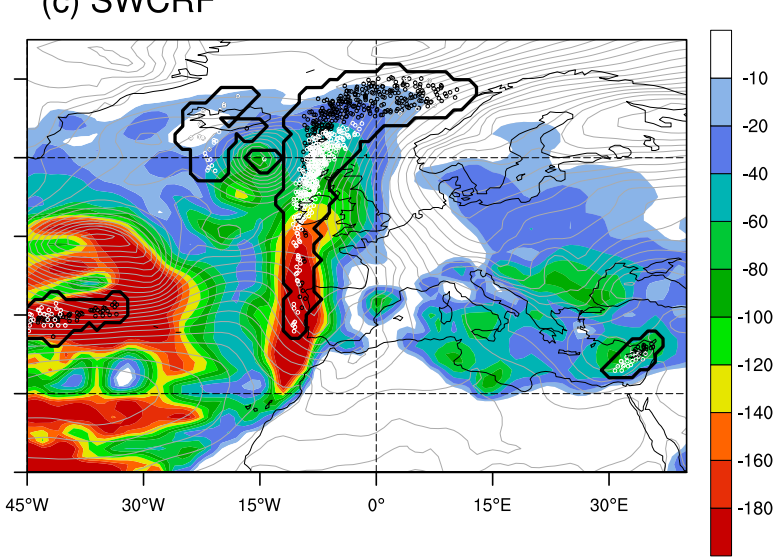

(e) NetCRF

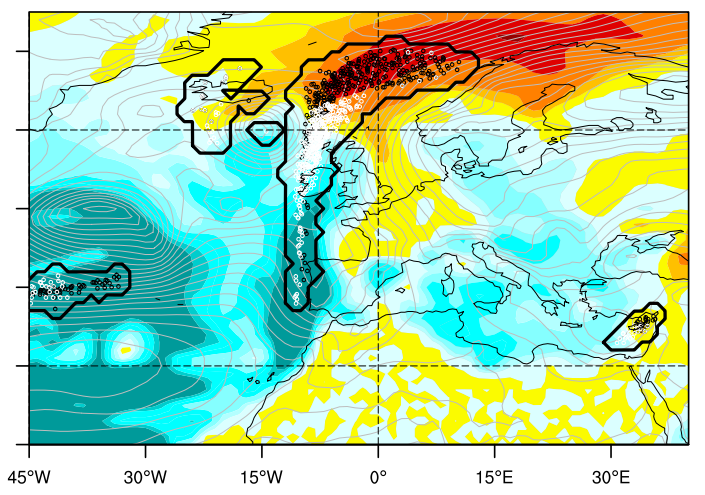

$\left[\mathrm{g} \mathrm{m}^{-2}\right]$

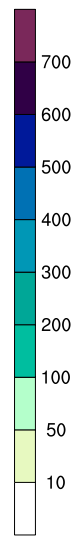

$\left[\mathrm{W} \mathrm{m} \mathrm{m}^{-2}\right]$

$\left[\mathrm{W} \mathrm{m} \mathrm{m}^{-2}\right]$

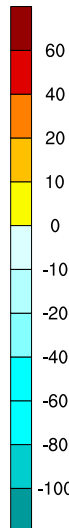

(b) TIW

[g $\left.\mathrm{m}^{-2}\right]$

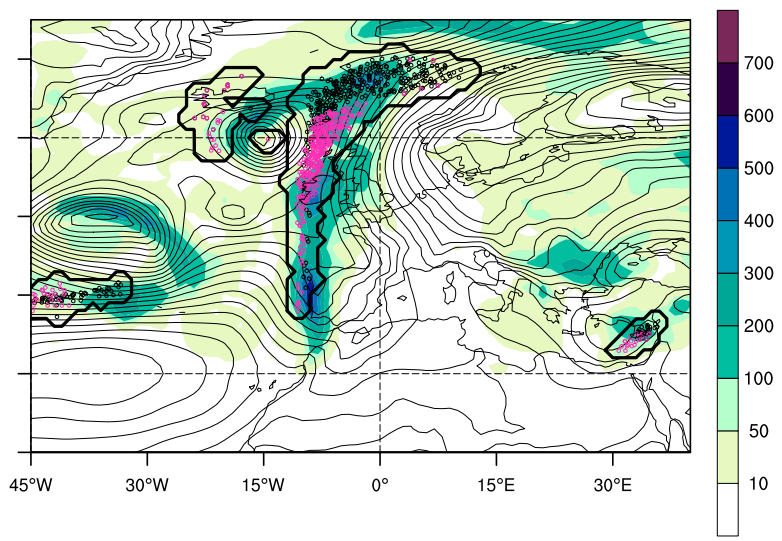

(d) LWCRF

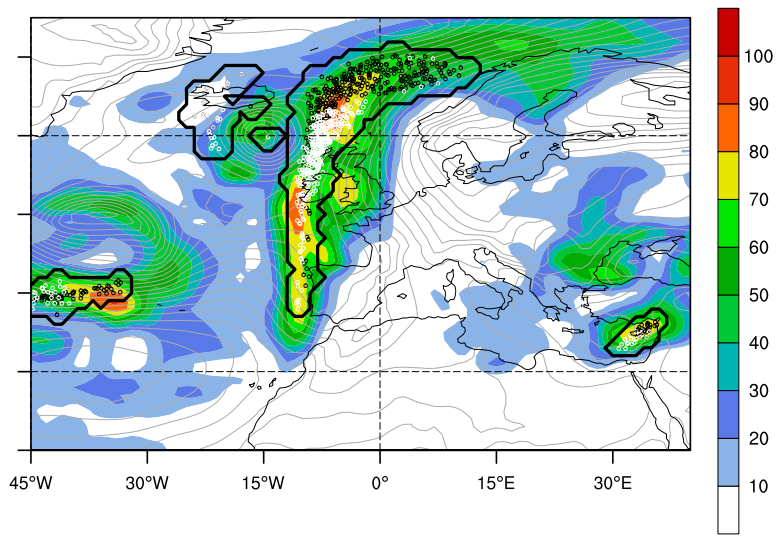

(f) NetCRF CERES

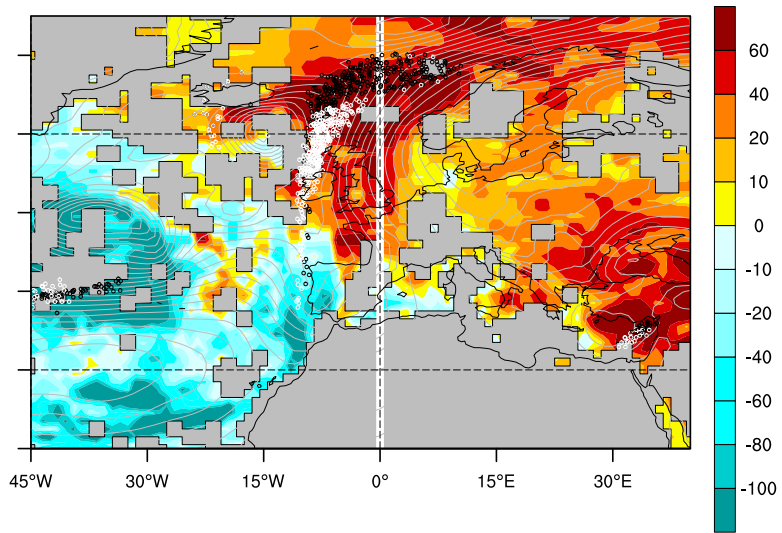

FIG. 4. (a) TLW (colored), (b) TIW (colored), (c) SWCRF (colored), (d) LWCRF (colored), (e) NetCRF (colored), and (f) CERES NetCRF (colored), SLP (thin black or gray lines), and position of WCB air parcels for 1800 UTC 30 Jan 2009 (black) and 1200 UTC 30 Jan 2009 (pink or white). The thick black line encloses the whole area, which is associated with a WCB at 1800 UTC 30 Jan 2009. In (f), the gray shaded areas denote missing data in the CERES dataset. 
strongly dominant leading to a strongly negative NetCRF of more than $-100 \mathrm{~W} \mathrm{~m}^{-2}$. However, at latitudes north of $60^{\circ} \mathrm{N}$, LWCRF dominates due to the polar night. This transition from negative to positive NetCRF values along the ascending airstream has also been seen in Fig. 3e. In addition, in Fig. 4f NetCRF based on CERES data is shown. As for the ERA-Interim data, at the equatorward tip of the WCB, SWCRF is dominant leading to a negative NetCRF, which is however less pronounced compared to ERA-Interim. The transition to positive NetCRF values occurs already more equatorward in the satellite data. The values of NetCRF are larger compared to ERA-Interim whereas the main difference rises from larger values in LWCRF. The main feature of a transition from negative to positive NetCRF can, however, be seen in both datasets. Thus, due to its pronounced poleward motion, the WCB can produce a transition from negative to positive NetCRF values along the rising trajectories and does not lead to a uniform radiative forcing along its ascent.

In the following, we investigate the time evolution of the considered variables along all WCB trajectories in the climatology.

\section{Climatological results}

\section{a. Time evolution of total condensate and CRF along $W C B$ trajectories}

To evaluate the effect of WCBs on the formation of condensate and radiative forcing, the time evolution of TLW, TIW, SWCRF, LWCRF, and NetCRF is shown as a mean over all WCBs in the whole period from 1979 to 2010. The analysis has been done separately for the Northern and Southern Hemispheres as well as boreal winter (DJF) and summer (JJA). In addition to quantifying the evolution of all variables along the WCB trajectories $\left[\Psi_{\mathrm{WCB}}(t)\right.$ in Eq. (1)], the mean values at each time step from $t=0$ to $48 \mathrm{~h}$ are related to the climatological values at the same grid points $\left[\Psi_{\text {CLIM }}(t)\right.$ in Eq. (1)]. Therefore, at every $6 \mathrm{~h}$ time step during the whole climatology we select all grid points where there is a WCB air parcel at a given time step, for example, at $t=0 \mathrm{~h}$. At these grid points we then select the values of the climatology of the variable of interest (e.g., TLW). Finally, we calculate the mean over all grid points, which are linked to a WCB, separately for every time step (from $t=0$ to $48 \mathrm{~h}$ ), which leads to one single value for each time step along the WCB ascent. Additionally, at every grid point we calculate the standard deviation of the climatology based on daily mean values of all variables. After that we again select for every $6 \mathrm{~h}$ time step during the whole climatology all grid points where there is a WCB air parcel at a given time step ( $t=0$ to $48 \mathrm{~h}$ ) and calculate the mean value over all these time steps and grid points where there is a WCB from time $t=0$ to $48 \mathrm{~h}$ separately $\left[\sigma_{\Psi}(t)\right.$ in Eq. (1)]. In total we then obtain nine values (from $t=0$ to $48 \mathrm{~h}$ ) for the WCB $\left(\Psi_{\mathrm{WCB}}\right)$, the climatology $\left(\Psi_{\text {CLIM }}\right)$, and the standard deviation $\left(\Psi_{\sigma}\right)$ at WCB grid points. Finally, we calculate the normalized difference $d$ for each time step separately with

$$
d(t)=\frac{\Psi_{\mathrm{WCB}}(t)-\Psi_{\mathrm{CLIM}}(t)}{\sigma_{\Psi}(t)}, \quad t=0, \ldots, 48 \mathrm{~h},
$$

where $t$ denotes the nine time steps from $t=0$ to $48 \mathrm{~h}$ and $\Psi$ represents the variables of interest, thus TLW, TIW, SWCRF, LWCRF, and NetCRF.

In Fig. 5 the results are shown for the winter months of each hemisphere (DJF for the Northern Hemisphere and JJA for the Southern Hemisphere). As already briefly discussed in the previous section, it can be seen that TLW and TIW strongly increase when the WCB air parcels start their ascent, whereas TLW reaches higher values as compared to TIW in both hemispheres. TLW reaches its maximum already after $12 \mathrm{~h}$ whereas the maximum in TIW only occurs slightly later when the air parcels are already higher up in the atmosphere at colder temperatures. Colored points indicate the deviation from the climatological values in means of standard deviation. Whenever a WCB rises and leads to the formation of clouds, the associated values of TLW and TIW deviate up to $3 \sigma$ from the climatological values. The same signal can be seen for LWCRF and SWCRF. With increasing total condensate, LWCRF (SWCRF) also strongly increases (gets more negative), reaching values up to $60 \mathrm{~W} \mathrm{~m}^{-2}$ for LWCRF and $-70 \mathrm{~W} \mathrm{~m}^{-2}$ for SWCRF in both hemispheres. However, the deviation from the climatological mean values is smaller than for TLW and TIW. This is caused by the fact that for the total condensate values, the whole vertical column is taken into account. In contrast for CRF, a certain value of SWCRF can be reached already when radiation is reflected back to space only from the upper part of a cloud. Clouds can become very reflective and exhibit strong SWCRF without being strongly extended in the vertical. Thus, at a certain point, SWCRF does not get more negative when the vertical extent of the cloud further increases because SWCRF gets saturated for a certain cloud height. This is in contrast to the values of total condensate that are getting larger with increasing cloud height. Therefore, the deviation from the climatological values remains below the ones for total condensate. The resulting NetCRF can be seen in Fig. 5e. In both hemispheres, NetCRF is negative during the first 24 to $30 \mathrm{~h}$ of the ascent, thus showing that the high reflectivity of the associated cloud band dominates the NetCRF. As 

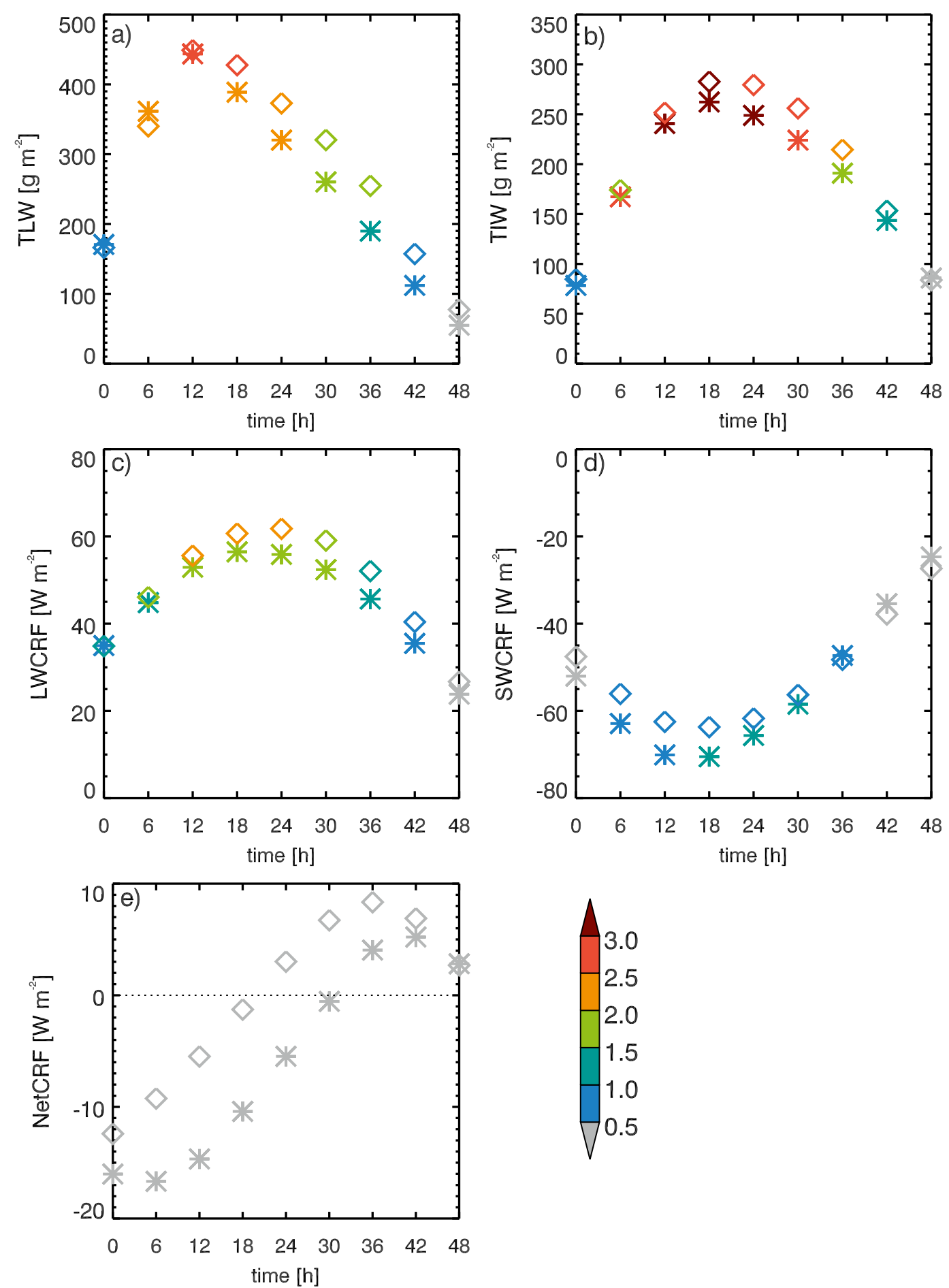

FIG. 5. Time evolution along WCB trajectories of (a) TLW, (b) TIW, (c) LWCRF, (d) SWCRF, and (e) NetCRF. The values for the Northern (Southern) Hemisphere winter months DJF (JJA) are shown as asterisks (diamonds). Color coding shows the normalized difference as described in Eq. (1).

WCBs travel poleward, there is no sunlight in high latitudes in the winter hemispheres. Therefore, the LWCRF starts to dominate at the end of the WCB ascent and NetCRF gets positive. In the Southern
Hemisphere, LWCRF is slightly more positive and SWCRF slightly more negative, thus the resulting NetCRF is shifted 5 to $10 \mathrm{~W} \mathrm{~m}^{-2}$ toward more positive values. However, in both hemispheres there is a 

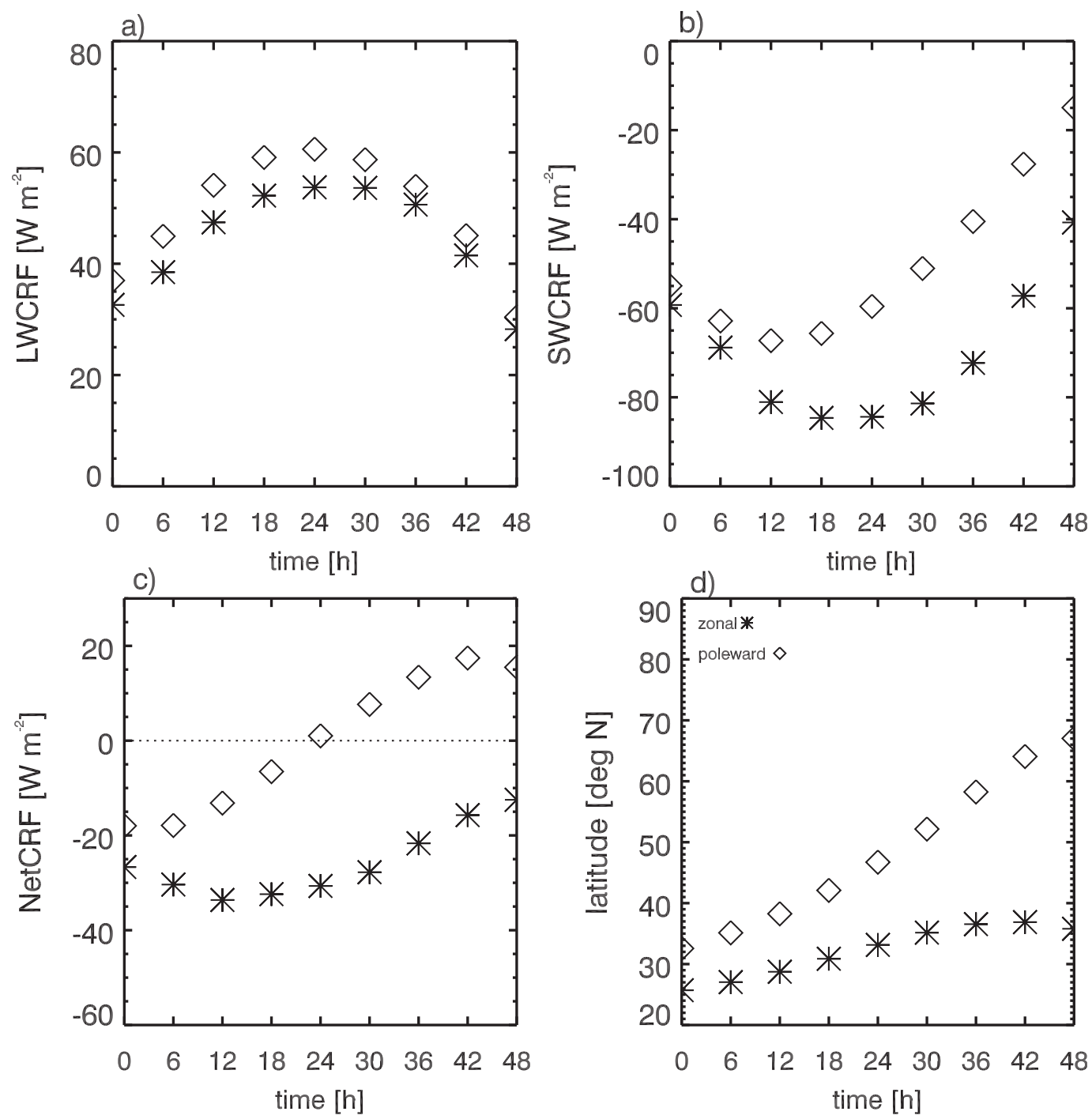

FIG. 6. Time evolution along WCB trajectories of (a) LWCRF, (b) SWCRF, (c) NetCRF, and (d) latitude. The values for zonal moving WCB trajectories (lat $<50^{\circ} \mathrm{N}$ at all times during the ascent) is shown as asterisks. Poleward moving WCB trajectories [lat $(t=0 \mathrm{~h})-\operatorname{lat}(t=48 \mathrm{~h})>30^{\circ}$ and $\operatorname{lat}(t=48 \mathrm{~h})>65^{\circ} \mathrm{N}$ ] are shown as diamonds.

difference of $\sim 20 \mathrm{~W} \mathrm{~m}^{-2}$ in NetCRF from the WCB inflow to outflow. The deviation from the climatological mean values when averaged over the whole hemisphere remains below 0.5 standard deviations. SWCRF as well as LWCRF exhibit larger values as compared to the climatology whereas in the resulting NetCRF this effect is canceled.

The shift from negative to positive NetCRF along the WCB ascent is influenced by the poleward motion but also by the strong ascent of the WCB. To investigate the importance of ascent versus poleward motion of WCBs, we selected WCB trajectories in the Northern Hemisphere that stay south of $50^{\circ} \mathrm{N}$ during their $48 \mathrm{~h}$ ascent and compared them to trajectories that travel at least $30^{\circ}$ northward and end to the north of $65^{\circ} \mathrm{N}$. Thus we can compare the time evolution of SWCRF, LWCRF, and NetCRF along zonal and poleward traveling WCBs. The results can be seen in Fig. 6. LWCRF exhibits slightly higher values along poleward traveling WCBs (see Fig. 6a) due to slightly more TIW along these trajectories (not shown). However, the differences are small and mainly restricted to the first $30 \mathrm{~h}$ of the ascent. In contrast, the time evolution of SWCRF strongly differs between zonal and poleward moving WCBs (see Fig. 6b). At the start of the trajectories SWCRF exhibits similar values of -55 to $-60 \mathrm{~W} \mathrm{~m}^{-2}$ as the starting latitude for both trajectory subgroups is located around $\sim 30^{\circ} \mathrm{N}$ (see Fig. 6d). 

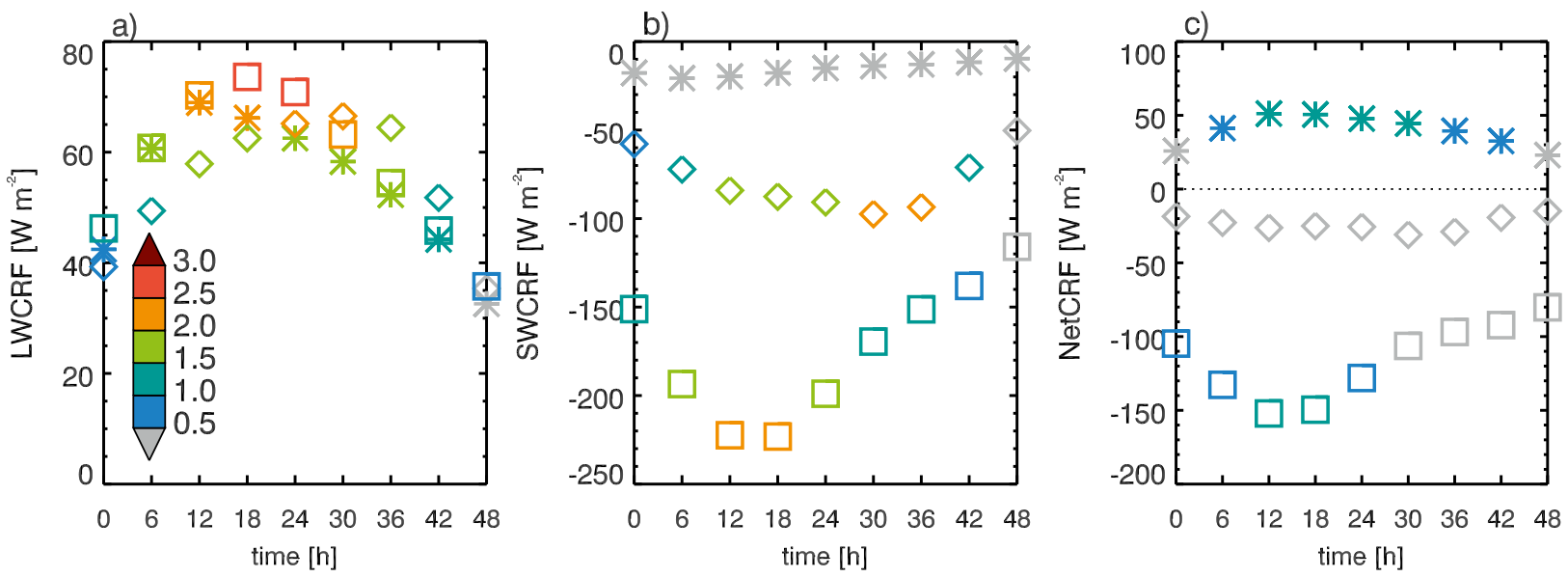

FIG. 7. As in Fig. 5, but only for (a) LWCRF, (b) SWCRF, and (c) NetCRF averaged over three regions representing the entrance (NA-S, diamonds) and exit (NA-N, asterisks) regions of the North Atlantic storm track and the entrance region of the storm track in the South Atlantic (SA, squares). The three regions are shown by black boxes in Fig. 9a.

However, during the WCB ascent, SWCRF of the poleward-moving trajectories exhibits less negative values than the zonal-moving trajectories as they are located more poleward where there is less incoming solar radiation. Thus, in the WCB outflow, SWCRF in the zonal moving WCBs is twice as large compared to the poleward moving WCBs. However, for both trajectory bundles, SWCRF shows the typical time evolution as expected for WCBs. The formation of thick and bright cloud bands in the first $\sim 24 \mathrm{~h}$ that reflect the incoming solar radiation back to space leads to a strongly negative SWCRF along the ascent that decrease toward the WCB outflow where the clouds get optically thinner. The resulting NetCRF can be seen in Fig. 6c. The NetCRF along poleward moving WCBs is characterized by a shift from negative to positive NetCRF along the ascent. In contrast, zonal moving WCBs that are exposed to incoming solar radiation during their whole ascent exhibit negative NetCRF along the $48 \mathrm{~h}$ ascent and are thus dominated by SWCRF. The results thus nicely illustrate that the poleward motion of WCBs is a crucial ingredient in order to produce the observed dipole in NetCRF along the WCB ascent, although even zonal moving WCBs reveal a difference in NetCRF from the inflow to the outflow of $12 \mathrm{~W} \mathrm{~m}^{-2}$.

To better understand the effect of WCBs on NetCRF in different regions along the storm track, in Fig. 7 the mean over smaller regions representing the entrance and exit regions of the storm track are shown. In the North Atlantic entrance region (see black box NA-S in Fig. 9a), LWCRF (diamonds) strongly increases along the ascending WCBs and deviate up to 2.5 standard deviations from the climatological values.
The SWCRF exhibits values between -50 and $-100 \mathrm{~W} \mathrm{~m}^{-2}$ with deviations of more than $2 \sigma$. The resulting NetCRF is negative along the whole WCB ascent, however the values in this region do not significantly deviate from the climatological values. This is caused by the fact that the WCB starting regions at the entrance of the North Atlantic storm track are marked by high standard deviations. In the exit region (asterisks), LWCRF again strongly increases along the WCB and exhibits deviations of more than $2 \sigma$. The SWCRF is almost zero due to the missing sunlight at high latitudes. The resulting NetCRF is therefore determined by the LWCRF and shows values between 20 and $50 \mathrm{~W} \mathrm{~m}^{-2}$. These values deviate between $0.5 \sigma$ and $1.5 \sigma$ from the climatological mean values showing that in this region WCBs lead to an increased positive NetCRF. In contrast, in the storm track entrance region in the South Atlantic, SWCRF (squares) strongly dominates NetCRF leading to values between -100 and $-170 \mathrm{~W} \mathrm{~m}^{-2}$ along WCBs. These strongly negative values are produced by the bright WCB cloud bands and the availability of sunlight in this region and season, despite large standard deviations in the WCB starting regions. As the storm track in the Southern Hemisphere is very symmetric around Antarctica, no clear exit region exists and the analysis has only been done for the South Atlantic entrance region. These results nicely show that the effect of WCBs on NetCRF is not uniformly distributed along its ascent and the storm track regions. Instead in the WCB inflow regions in low latitudes, the cooling effect of clouds dominates whereas in outflow regions in higher latitudes, the greenhouse effect of clouds is the dominant process. 

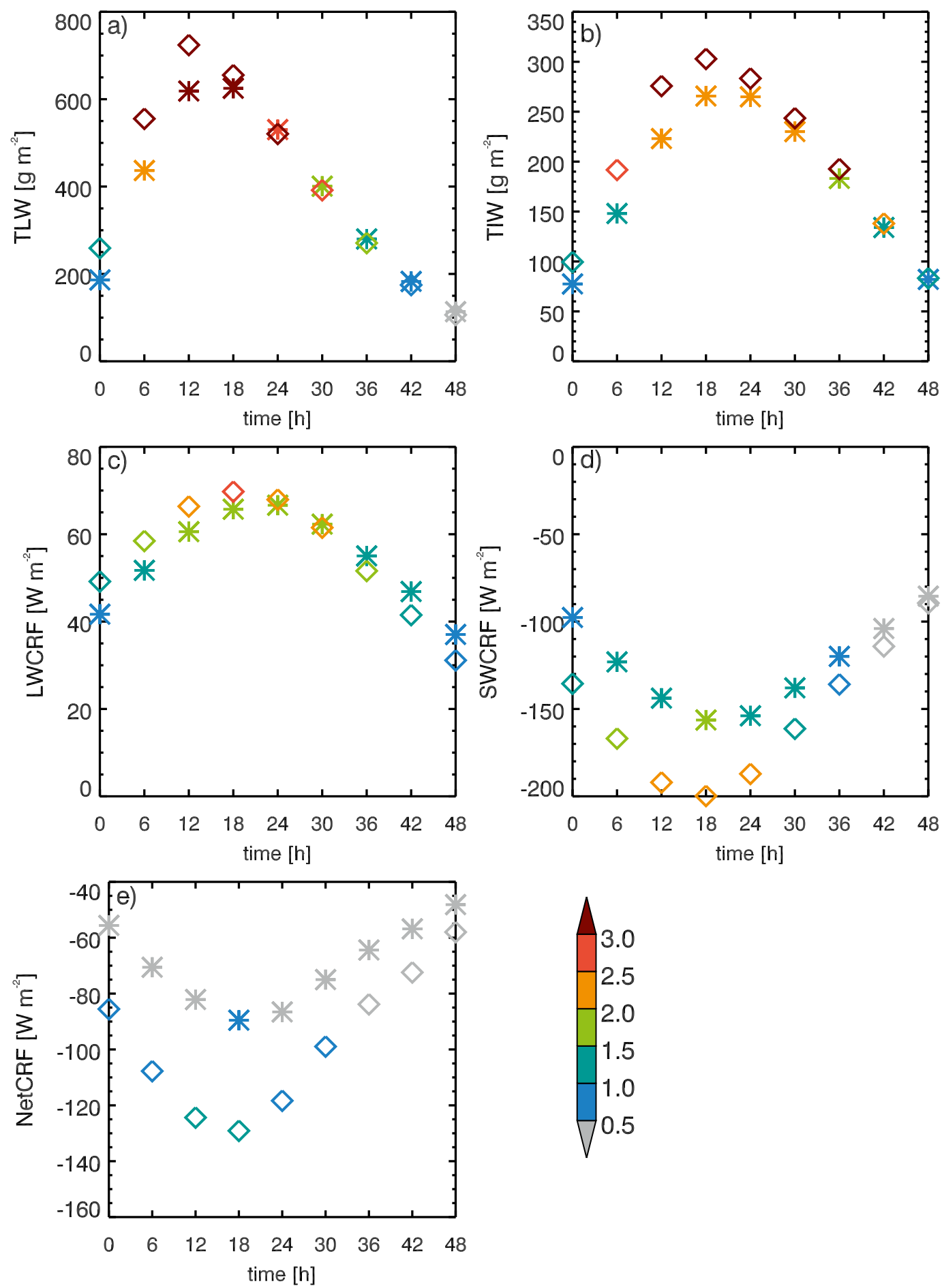

FIG. 8. As in Fig. 5, but for the Northern (Southern) Hemispheric summer months JJA (DJF).

In summer, shown in Fig. 8, the rising WCB airstreams also lead to the formation of high total condensate values which deviate more than $3 \sigma$ from the climatological values, although due to the higher summer temperatures TLW (TIW) is larger (smaller) than during the winter months. The formation of highly reflective thick clouds together with the availability of sunlight during summer leads to a pronounced SWCRF that 
exceeds the corresponding LWCRF. The resulting NetCRF is therefore strongly negative along the whole WCB ascent with peak values of $\sim-130 \mathrm{~W} \mathrm{~m}^{-2}$ in the Southern Hemisphere and $-90 \mathrm{~W} \mathrm{~m}^{-2}$ in the Northern Hemisphere around $t=18-24 \mathrm{~h}$.

As the effect of WCBs on NetCRF is not uniformly distributed over the whole hemisphere and only small signals can be seen in regionally averaged values, we investigate the geographical pattern of WCB related NetCRF which is shown in the next section.

\section{b. Contribution of WCBs to the climatological signal}

\section{1) THE CONCEPT}

To disentangle the contribution of WCBs to the climatological mean values of TLW, TIW, LWCRF, SWCRF and NetCRF, the climatological values at each grid point are decomposed according to the following equation:

$$
\Psi_{\mathrm{CLIM}}=\left(\Psi_{\mathrm{WCB}} \times f_{\mathrm{WCB}}\right)+\Psi_{\text {NOWCB }} \times\left(1-f_{\mathrm{WCB}}\right),
$$

where $\Psi_{\text {CLIM }}$ denotes the climatological mean value of variable $\Psi$ at a certain grid point, $\Psi_{\mathrm{WCB}}$ the value of variable $\Psi$ at a certain grid point averaged over all time steps when the considered grid point is part of a WCB, $\Psi_{\text {NOWCB }}$ the value of variable $\Psi$ at a certain grid point averaged over all time steps when the considered grid point is not part of a $\mathrm{WCB}$, and $f_{\mathrm{WCB}}$ the frequency of occurrence of WCBs at a certain grid point. This equation can also be written as

$$
\Psi_{\mathrm{CLIM}}=\Psi_{\mathrm{NOWCB}}+\left(\Psi_{\mathrm{WCB}}-\Psi_{\text {NOWCB }}\right) \times f_{\mathrm{WCB}} .
$$

Thus, the climatological signal can be decomposed into a signal produced by an atmosphere without WCBs $\left(\Psi_{\text {NOWCB }}\right)$ plus a contribution from WCBs, which is the product of the "WCB effect" $\left(\Psi_{\mathrm{WCB}}-\right.$ $\left.\Psi_{\text {NOWCB }}\right)$ and the frequency of occurrence of WCBs $\left(f_{\mathrm{WCB}}\right)$. With such a decomposition it is possible to determine the contribution of WCBs to the total condensate and radiative forcing in the extratropical storm-track regions.

To determine the grid points at every time step that are associated with a WCB, we slightly enlarged the area which we consider to be related to a WCB. The cloud band which is associated with a WCB is not well represented by the core airstream that ascends $600 \mathrm{hPa}$, which is the definition of WCBs used in this study. Instead, clouds are also forming in air masses that ascend less than $600 \mathrm{hPa}$ and thus the cloud band surrounding the core WCB is associated to it. We therefore consider the cloud band surrounding the core in a radius of $100 \mathrm{~km}$ to be related to WCBs as well. Only taking the trajectory positions themselves as WCB related clouds would partially lead to small unconnected WCB related cloud regions within a region of continuous cloud cover. To calculate the WCB-related CRF, we therefore interpolate the unregularly distributed WCB trajectory positions to a regular grid at every 6-hourly time step during the whole ERA-Interim period. The gridding is done by smearing out every trajectory position using a $100 \mathrm{~km}$ radius. The resulting WCB-related area can be seen with the thick black lines in Fig. 4. However, it has to be mentioned that even with a $100 \mathrm{~km}$ smoothing radius, the $\mathrm{WCB}$ related cloud area is probably too small, especially in the WCB outflow region. When the WCB air parcels reach the upper troposphere, they are advected with the jet and travel large distances. As the ERA-Interim data are only available every $6 \mathrm{~h}$, there is a gap between the WCB air parcels that already reached the upper troposphere and traveled far to the northeast of the cyclone and the ones which are still located at midlevels at the cold or warm front. However, in reality, the whole area in between these air parcels would be filled by WCB air masses and therefore the whole CRF in this region should be associated to the WCB. Thus, with our method we miss these areas because the WCB outflow strongly diverges in the upper troposphere.

\section{2) Results IN DJF}

Figure 9 shows the results for DJF. The climatology of NetCRF (Fig. 9a) reveals that around $\sim 45^{\circ} \mathrm{N}$, NetCRF changes sign from negative values at low latitudes to positive values at high latitudes. In contrast, in the Southern Hemisphere, NetCRF is strongly negative due to the availability of solar radiation in summer. Furthermore, maxima in NetCRF can be found in the North Atlantic and North Pacific with values up to $30 \mathrm{~W} \mathrm{~m}^{-2}$. Thus, clouds produce a strong cooling in the summer hemisphere and a pronounced meridional gradient in the winter hemisphere, which is particularly strong in the Atlantic and Pacific storm-track regions. In Fig. 9b, NetCRF without the effect of WCBs is shown [NetCRF $\left.\mathrm{NOWCB}_{\mathrm{NO}} \times\left(1-f_{\mathrm{WCB}}\right)\right]$. In the tropics, where no WCBs occur, NetCRF ${ }_{\text {NOwCB }}$ equals the climatological values. However, in the storm-track regions the meridional gradient of $\mathrm{NetCRF}_{\mathrm{NOWCB}}$ is weaker and the maxima in the North Pacific and Atlantic (especially around Iceland) are less pronounced. In the Southern Hemisphere, NetCRF NOWCB $_{\text {reveals }}$ less negative values and thus a weaker meridional gradient can be seen around the whole Antarctic continent. In Fig. 9c, the WCB effect given by $\mathrm{NetCRF}_{\mathrm{WCB}}-\mathrm{NetCRF}_{\text {NOwCB }}$ is shown. Here, the results are only displayed where $f_{\mathrm{WCB}}$ is larger than $5 \%$ (see gray lines in Fig. 9c). The figure nicely reveals that 
(a) CLIM

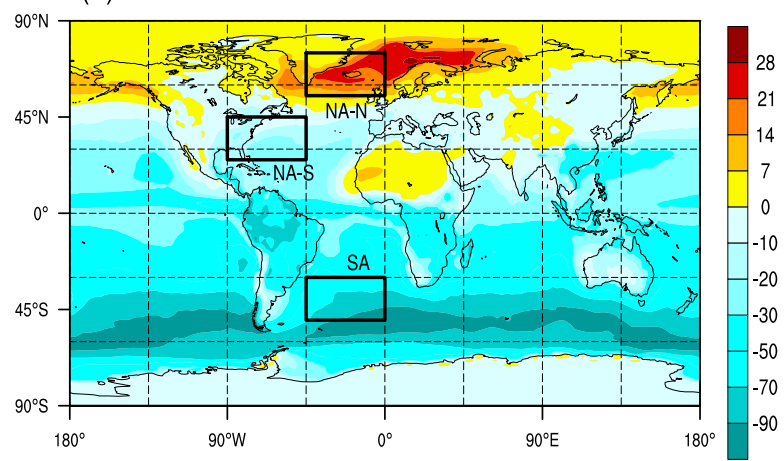

(c) WCB - NOWCB

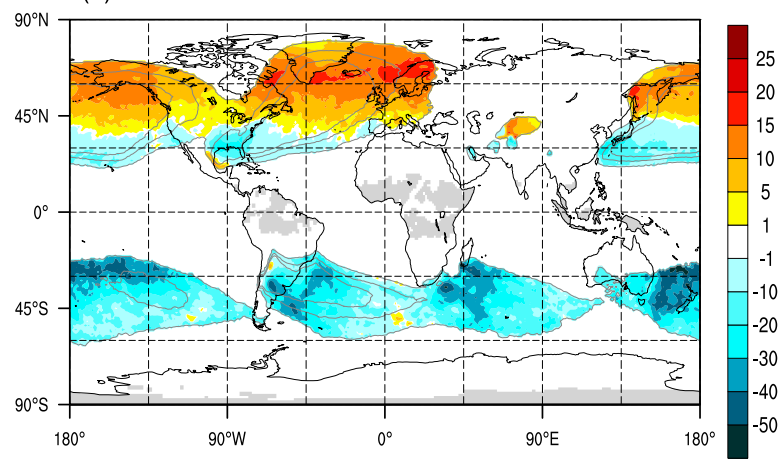

(b) NOWCB * $\left(1-f_{W C B}\right)$

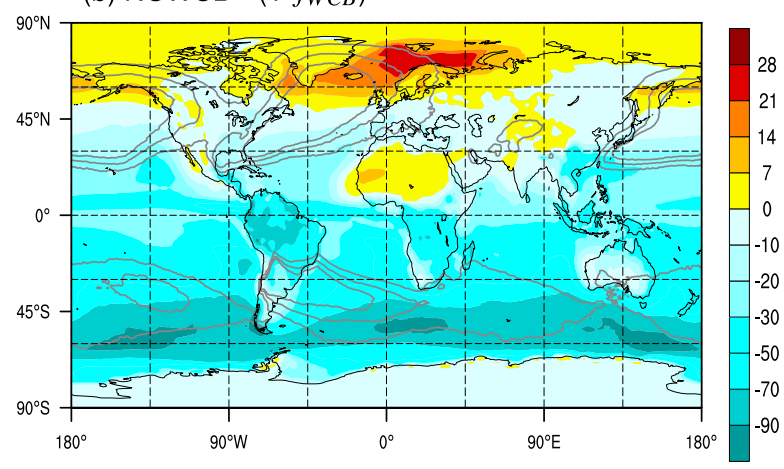

(d) $\mathrm{WCB}^{*} f_{W C B}$

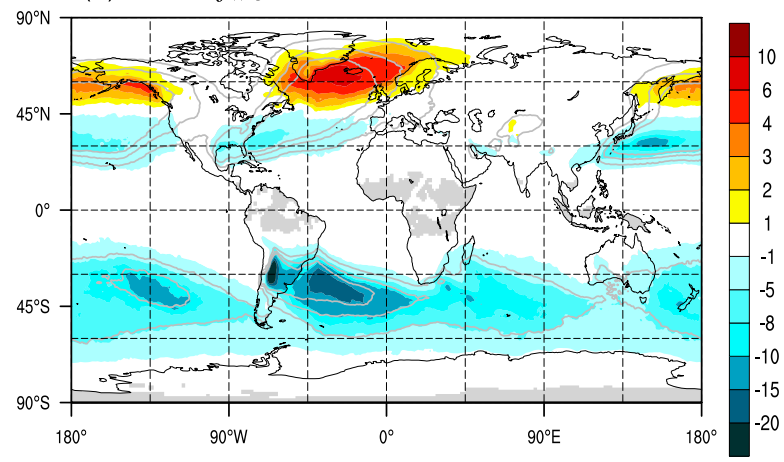

FIG. 9. (a) Climatology of NetCRF for DJF, (b) mean NetCRF averaged over all times without WCBs multiplied with the frequency when there is no WCB at a certain grid point $\left[\Psi_{\mathrm{WCB}} \times\left(1-f_{\mathrm{WCB}}\right)\right],(\mathrm{c})$ difference of NetCRF averaged over all times with WCB and all times without WCBs $\left(\Psi_{\mathrm{WCB}}-\Psi_{\mathrm{NOWCB}}\right)$ shown only for grid points with $f_{\mathrm{WCB}}>5 \%$, and (d) mean NetCRF at times when a WCB occurs multiplied with the frequency of occurrence of WCBs $\left(\Psi_{\mathrm{WCB}} \times f_{\mathrm{WCB}}\right)$. Gray lines denote $f_{\mathrm{WCB}}$ with lines for $5 \%, 10 \%$, and $15 \%$. Black boxes show the areas used for Fig. 7.

the effect of WCBs is to decrease the negative NetCRF in their main inflow regions in the Gulf of Mexico, along the U.S. East Coast, and along $30^{\circ} \mathrm{N}$ in the North Pacific. On the other hand, they strongly contribute to the North Atlantic and Pacific maxima. Therefore, the effect of WCBs in the winter hemisphere is to strengthen the meridional gradient in NetCRF in the main storm-track regions. As the WCB outflow is located far north, they also contribute to the observed North Atlantic maximum in NetCRF. In contrast, in the Southern Hemisphere summer, WCBs strongly decrease the already negative NetCRF. The pattern is more zonally uniform than in the Northern Hemisphere due to the differences in the land sea distribution and the associated storm tracks in both hemispheres. In Fig. 9d, we additionally show the absolute contribution of WCBs to the total NetCRF given by NetCRF $\mathrm{WCB}_{\mathrm{WC}} \times f_{\mathrm{WCB}}$. WCBs strongly contribute to the North Atlantic maximum with more than $6 \mathrm{~W} \mathrm{~m}^{-2}$. Furthermore, they decrease the negative NetCRF in the subtropical North Atlantic and Pacific by up to $-10 \mathrm{Wm}^{-2}$. In the Southern Hemisphere, WCBs contribute with more than $-10 \mathrm{Wm}^{-2}$ to the NetCRF, especially east of South America where WCBs are very frequent. Thus, these figures show that WCBs contribute strongly to both negative and positive NetCRF and therefore might be able to influence the meridional temperature gradient and thus the dynamics in the storm-track regions.

\section{3) Results In JJA}

Figure 10 displays the results for JJA. It can be seen that the climatology of NetCRF (Fig. 10a) is dominated by the SWCRF in the entire Northern Hemisphere. In summer, clouds lead to a pronounced cooling effect with maxima in the Atlantic and Pacific storm-track regions. In the Southern Hemisphere, poleward of $\sim 50^{\circ} \mathrm{S}$, LWCRF dominates due to lack of sunlight. High positive values of LWCRF occur almost uniformly around Antarctica. NetCRF excluding the effect of WCBs $\left[\mathrm{NetCRF}_{\mathrm{NOWCB}} \times\left(1-f_{\mathrm{WCB}}\right)\right.$; Fig. 10b] shows that the values are in most parts of the globe very similar to the climatology except for the North Pacific storm track where SWCRF is less negative compared to the climatology and around Antarctica where LWCRF is 
(a) CLIM

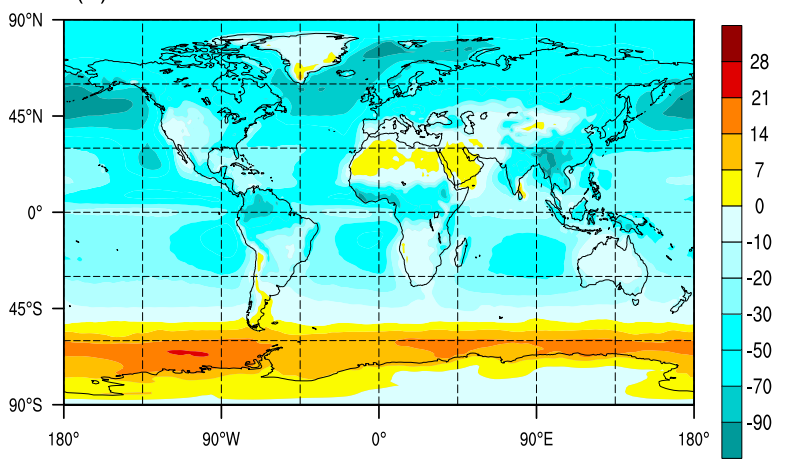

(c) WCB - NOWCB

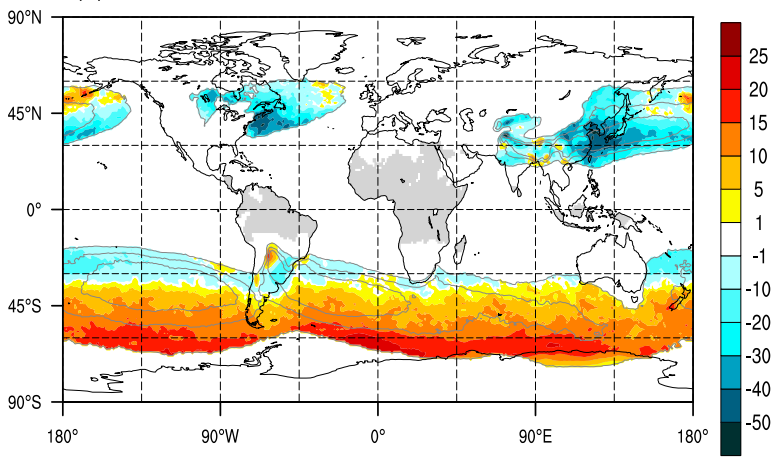

(b) NOWCB * $\left(1-f_{W C B}\right)$

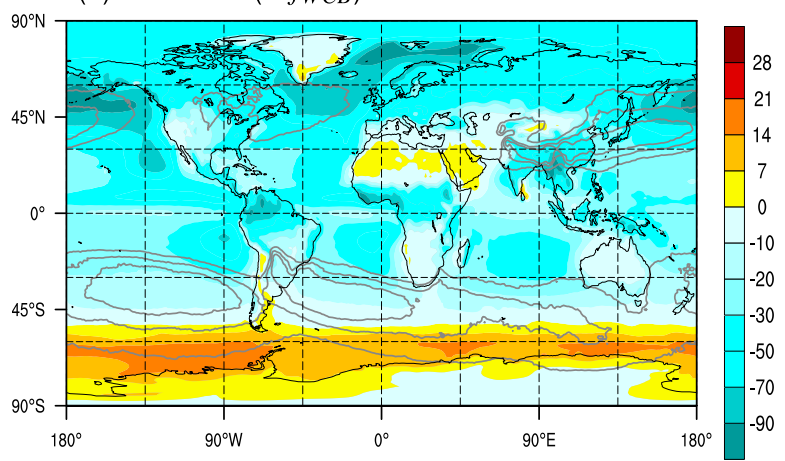

(d) WCB * $f_{W C B}$

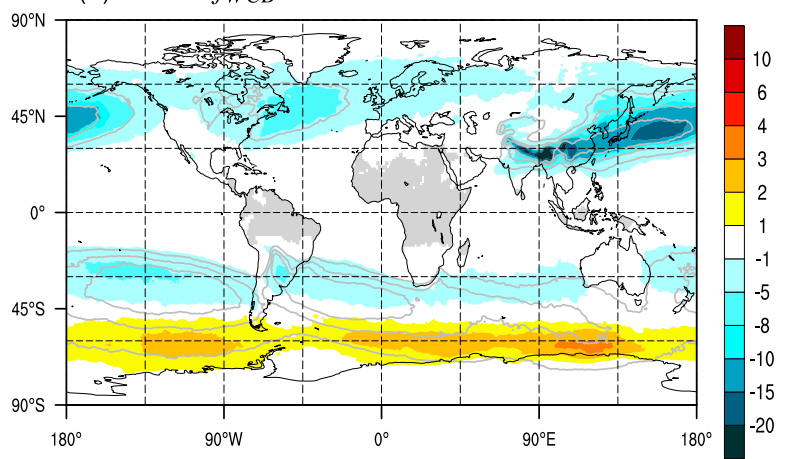

FIG. 10. As in Fig. 9, but for JJA.

less positive. Figure 10c shows the WCB effect $\left(\mathrm{NetCRF}_{\mathrm{WCB}}-\mathrm{NetCRF}_{\mathrm{NOWCB}}\right)$. It can be seen that WCBs lead to a decrease of SWCRF in the main starting regions in the western parts of the North $\mathrm{Pa}$ cific and Atlantic. In the Southern Hemisphere, WCBs lead to a small region with more negative SWCRF at the equatorward side of their ascent region and to a strong increase in LWCRF around Antarctica. The absolute contribution of WCBs to the climatological values $\left(\mathrm{NetCRF}_{\mathrm{WCB}} \times f_{\mathrm{WCB}}\right)$ is shown in Fig. 10d. In the regions with their highest frequency of occurrence in the North Pacific, WCBs contribute with more than $-15 \mathrm{~W} \mathrm{~m}^{-2}$ to the climatology of NetCRF. Even in the North Atlantic, where $f_{\mathrm{WCB}}$ does not exceed $5 \%$ (see gray line), WCBs still contribute with more than $-6 \mathrm{~W} \mathrm{~m}^{-2}$ to the climatology. This is caused by the fact that whenever a WCB occurs in this region, the associated SWCRF can be several standard deviations more negative than the climatological value such that even a small amount of WCBs has the potential to modify the radiative budget regionally.

\section{4) VALIDATION WiTH CERES SATELLITE DATA}

The same analysis has been done for CERES satellite data, which provide LWCRF, SWCRF and NetCRF every $6 \mathrm{~h}$ starting from 2001. In Fig. 11a, the climatology of NetCRF is shown for DJF. Although the absolute values are higher in CERES compared to ERA-Interim and despite regional differences, the overall pattern of positive NetCRF values north of $\sim 45^{\circ} \mathrm{N}$ with a pronounced maximum in the North Atlantic agrees very well. Also the band around Antarctica with strong SWCRF is almost the same in both datasets. One reason for discrepancies between the two datasets could be the underestimation of cloud cover in the ERA-Interim dataset. However a detailed analysis of the observed differences is beyond the scope of this paper. The mean over all time steps without WCBs $\left[\mathrm{NetCRF}_{\mathrm{NOWCB}} \times\right.$ $\left(1-f_{\mathrm{WCB}}\right)$, Fig. 11b] shows a very similar pattern as the climatology but with slightly less positive values mainly in the Northern Hemispheric storm-track regions where WCBs are most frequent. Around Antarctica, NetCRF reveals less negative values due to the missing effect of WCBs. As in the ERA-Interim dataset, the WCB effect (Fig. 11c) is to strongly increase the positive LWCRF values over large regions of the North Atlantic and $\mathrm{Pa}-$ cific. The decreases (more negative values) in SWCRF at the southern edge of the WCB ascent regions are less pronounced compared to ERA-Interim. This is due to the fact that the transition from negative to positive NetCRF in the Northern Hemisphere is slightly shifted 
(a) CLIM

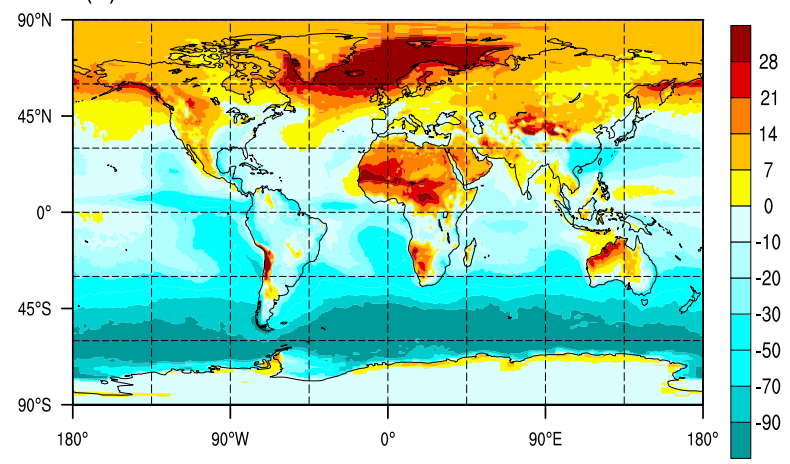

(c) WCB - NOWCB

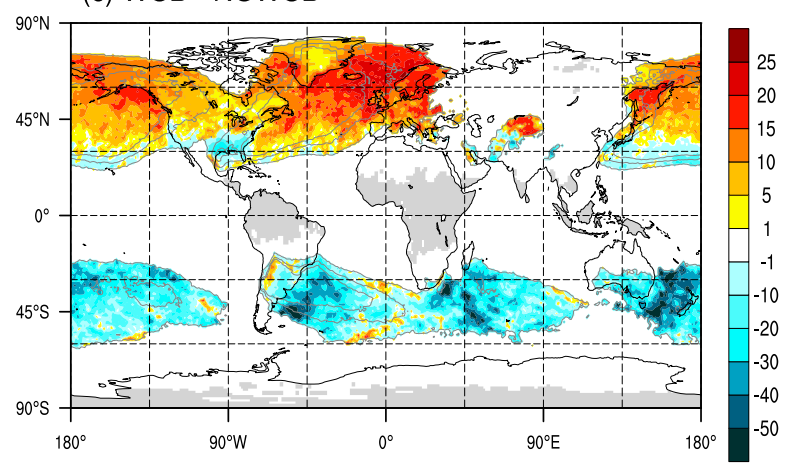

(b) NOWCB * $\left(1-f_{W C B}\right)$

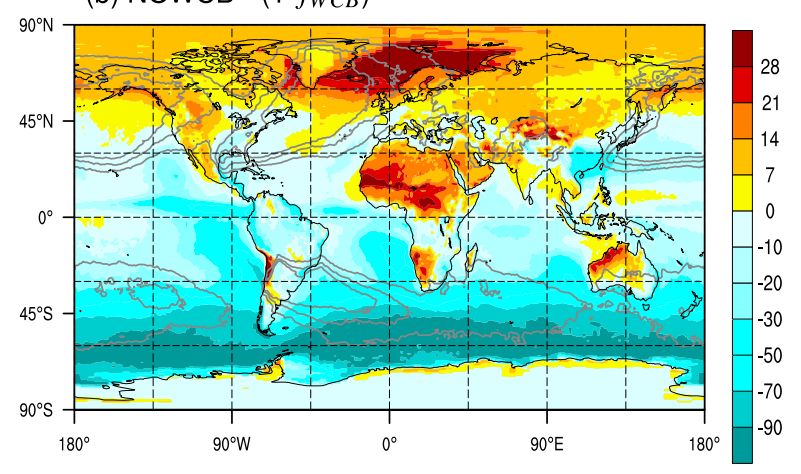

(d) $\mathrm{WCB} * f_{W C B}$

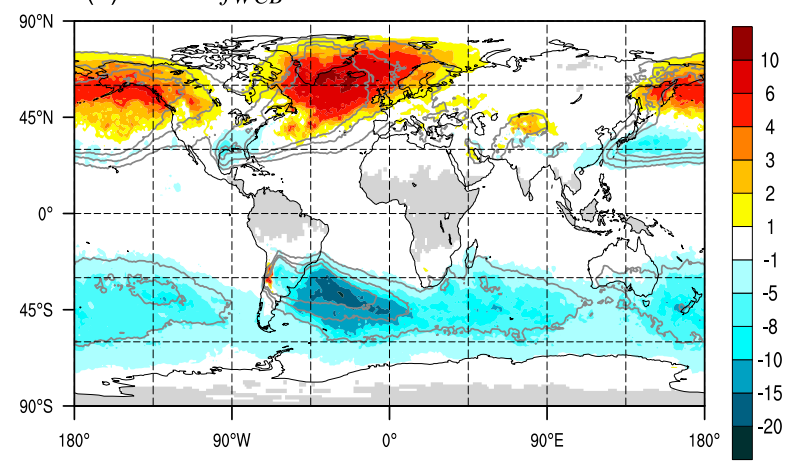

FIG. 11. As in Fig. 9, but for CERES satellite data covering the time period from 2001 to 2011.

to the south in the CERES data. Therefore, the WCB inflow regions in CERES are already located in the positive NetCRF areas. This implies that the WCBs do not start with a negative NetCRF but instead with a NetCRF close to zero. However, during their ascent they also exhibit a strong change in NetCRF with more than $20 \mathrm{~W} \mathrm{~m}^{-2}$ from the inflow to the outflow. In the Southern Hemisphere, WCBs lead to more negative values with maxima located east of South America, Africa, and Australia where WCBs are most frequent. Due to the low amount of valid data per grid point the fields show a noisier pattern than ERA-Interim. The contribution of WCBs to the climatology in absolute values $\left(\mathrm{NetCRF}_{\mathrm{WCB}} \times f_{\mathrm{WCB}}\right)$ is shown in Fig. 11d. Again, the results are similar to the ones obtained with the ERA-Interim dataset. WCBs lead to an increase in LWCRF in the North Atlantic of $6-10 \mathrm{Wm}^{-2}$. The values are slightly higher and the affected region is slightly larger in CERES than in ERA-Interim. Also in the North Pacific a pronounced positive contribution of more than $4 \mathrm{~W} \mathrm{~m}^{-2}$ is produced by WCBs. The negative contribution at the southwestern edge of the storm track in the North Atlantic covers a smaller region than in ERA-Interim due to the fact that the transition from negative to positive NetCRF occurs farther north in the
CERES data. However, in the WCB inflow regions in the North Pacific a strong negative contribution is produced by WCBs. In the Southern Hemisphere, WCBs produce a distinct negative signal almost around the entire Antarctic continent. East of South America, where WCBs are frequent ( $>15 \%$, see gray lines) they contribute with values of more than $-10 \mathrm{~W} \mathrm{~m}^{-2}$ to the strongly negative SWCRF. During JJA, shown in Fig. 12, the Northern Hemisphere is dominated by strong SWCRF with maxima in the North Atlantic and North Pacific storm tracks. Again very similar to the ERA-Interim results, WCBs strongly contribute to the negative NetCRF with more than $-10 \mathrm{~W} \mathrm{~m}^{-2}$ in the main WCB ascent regions. In the Southern Hemisphere they contribute with up to $4 \mathrm{Wm}^{-2}$ to the positive NetCRF in a belt around Antarctica (see Fig. 12d). Despite the much shorter time period of the CERES data, the overall conclusions drawn from the ERAInterim data are confirmed by the satellite data analysis.

\section{Summary and discussion}

In this study we investigate the link between WCBs and cloud radiative forcing in the extratropics. Therefore, the WCB climatology compiled by Madonna et al. 
(a) CLIM

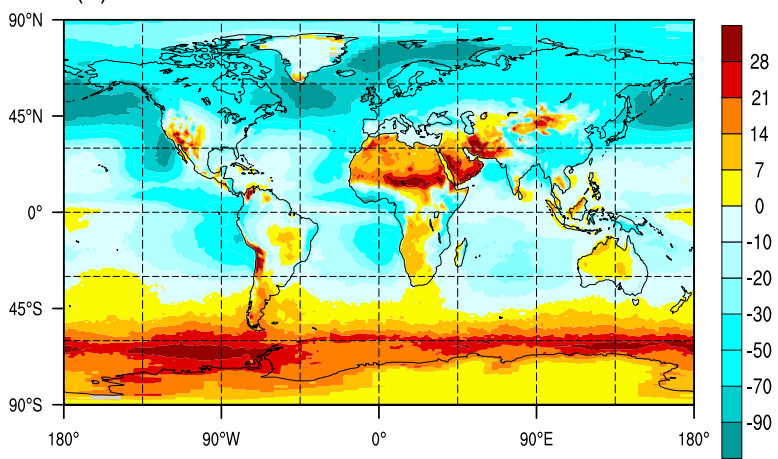

(c) WCB - NOWCB

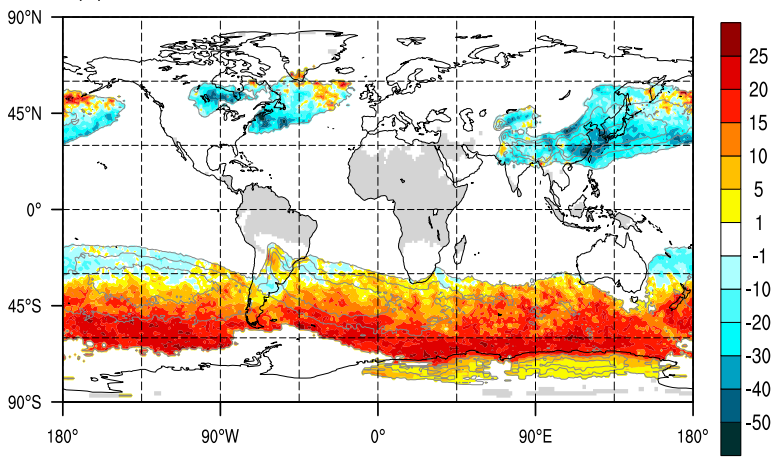

(b) NOWCB* $\left(1-f_{W C B}\right)$

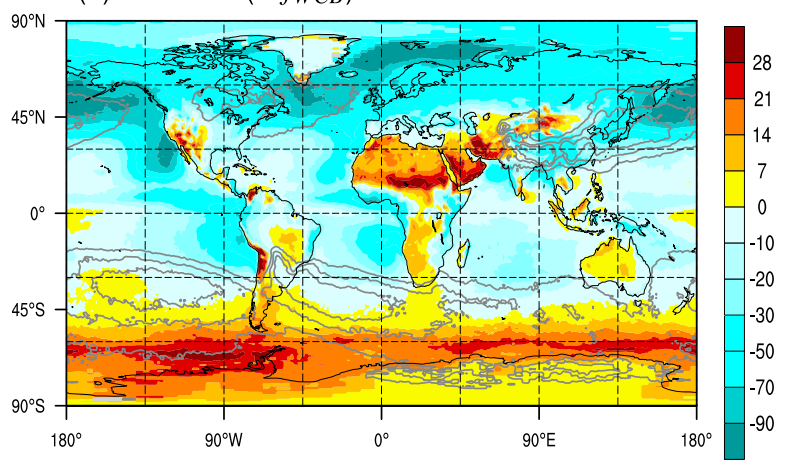

(d) $\mathrm{WCB}^{*} f_{W C B}$

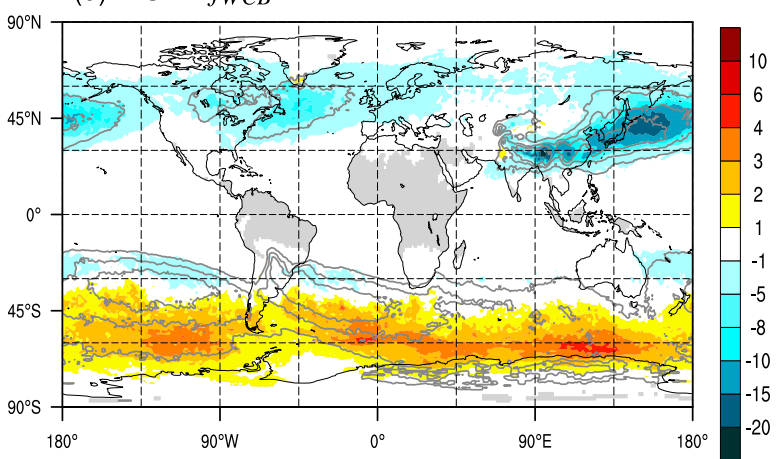

FIG. 12. As in Fig. 11, but for JJA.

(2014) is used, which is based on the ERA-Interim dataset covering the time span from 1979 to 2011. To link WCBs to the formation of clouds and cloud radiative forcing, shortwave, longwave and net cloud forcing have been calculated and traced together with total liquid and ice water along all WCB trajectories. This method allows for quantification of the contribution of WCBs to the formation of total condensate and cloud radiative forcing.

To introduce the concept of WCBs and its relation to TLW, TIW, and CRF, we first presented a case study of a WCB in the North Atlantic before we compiled a climatological analysis and quantified the contribution of WCBs to the climatological signals of net cloud forcing. The main results of this study can be summarized as follows:

- In an extratropical cyclone, the cloud bands are associated with very high values of TLW and TIW. In particular, the area along the cyclone's cold front, where the WCB exhibits its strongest ascent, is characterized by very high values of total condensate (TLW, TIW) and cloud radiative forcing (SWCRF, LWCRF, NetCRF) (see Fig. 4).

- Total condensate and CRF in the storm-track regions are highly variable in space and time and the climatological mean signal is produced by the superposition of highly variable weather systems like extratropical cyclones and their WCBs.

- From a climatological perspective, WCBs, as the main cloud-producing airstreams in extratropical cyclones, produce values of condensate (TLW, TIW) and cloud forcing (SWCRF, LWCRF) that deviate up to 2.5 standard deviations from the climatological mean (see Figs. 5 and 8).

- In the winter hemispheres, NetCRF strongly varies along the WCB ascent. In the inflow region SWCRF is dominant, leading to negative NetCRF, whereas in the outflow region LWCRF dominates due to a lack of incoming solar radiation $\left(\triangle \mathrm{NetCRF} \sim 20 \mathrm{~W} \mathrm{~m}^{-2}\right.$ from the inflow to the outflow in both hemispheres). Thus, WCBs do not produce a uniform NetCRF signal (see Fig. 5e).

- The strong poleward motion of WCBs is crucial for the formation of the dipole signature in NetCRF in winter (see Fig. 6).

- In the summer hemispheres, WCBs lead to strongly negative NetCRF due to the associated highly reflective cloud bands and the availability of solar radiation (see Fig. 8e).

- In the winter hemispheres, WCBs lead to a strengthening of the meridional gradient in NetCRF, which is 
particularly pronounced in the storm-track regions over the oceans (see Figs. 9c,d).

- In the North Atlantic, WCBs produce a positive NetCRF of more than $6 \mathrm{~W} \mathrm{~m}^{-2}$ and contribute to the climatological maximum of NetCRF in the North Atlantic sector in DJF (see Figs. 9c,d).

- In the summer hemispheres, WCBs contribute with more than $-10 \mathrm{~W} \mathrm{~m}^{-2}$ to the negative NetCRF around Antarctica and along the equatorward side of the storm tracks in the Northern Hemisphere, especially in the North Pacific (see Figs. 10c,d).

- The main conclusions are confirmed by an analysis of 10-yr satellite data (CERES) covering the timespan from 2001 to 2011 (see Figs. 9-12).

- Despite the large values of CRF associated with the cyclones' fronts, an essential part of CRF in the extratropics is not associated to cyclones and WCBs. In the climatological mean, WCBs account for $\sim 20 \%$ $-30 \%$ to the total CRF in the regions where they are most frequent, like the North Atlantic, Pacific, and the Southern Ocean (see Figs. 4, 9, 10).

- CRF associated with cirrus clouds occurring in the WCB outflow is underestimated. Here we only consider clouds to be related to the WCB along the $48 \mathrm{~h}$ ascent. However, cirrus clouds in the WCB outflow in the upper troposphere can exist longer and be advected over large areas. In our analysis these clouds are not related to the WCB, although they might lead to strong CRF, especially if they occur far poleward.

These results show that WCBs as main cloudproducing airstream in the extratropical storm track are important flow features that modify Earth's radiative budget. They are most frequent in winter when they produce a nonhomogeneous NetCRF along their ascent with negative NetCRF in the inflow and positive NetCRF in the outflow. Therefore they could have an impact on the horizontal temperature gradient (baroclinicity) in the extratropical storm tracks and thus on the formation and intensification of cyclones. Furthermore, due to the pronounced formation of total condensate, which is associated with strong latent heating, WCBs can have an impact on the intensification of extratropical cyclones (Binder et al. 2016). Due to these two effects, cloud formation and the atmospheric circulation are strongly linked. However, a better understanding of these feedback mechanisms is necessary in order to improve our knowledge about the response of the extratropical storm track to climate change (Shepherd 2014; Bony et al. 2015; Shaw et al. 2016).

Our results suggest that in order to investigate this feedback it is essential to correctly represent WCBs in climate models. This includes a correct representation of the location of the formation, ascent, and outflow regions as well as a correct representation of the frequency of occurrence of WCBs. Shifts in the position of WCBs as well as changes in their frequency can have significant impacts on radiation. Additionally, microphysical properties of clouds and their response to warmer temperatures in a future climate need to be simulated correctly. This concerns the microphysical properties of mixed-phase clouds in the ascent regions as well as cirrus clouds in the WCB outflow. Whether changes in NetCRF in a warmer climate are produced by changes in the underlying circulation and availability of moisture or if they are caused by changes in the clouds' microphysical properties remains unclear (Ceppi and Hartmann 2015; McCoy et al. 2018). The method of decomposing the climatological signal into a signal produced by an atmosphere without WCBs $\left(\Psi_{\text {NOWCB }}\right)$, the contribution from WCBs (WCB effect; $\left.\Psi_{\mathrm{WCB}}-\Psi_{\mathrm{NOWCB}}\right)$, and the frequency of WCBs $\left(f_{\mathrm{WCB}}\right)$ [see Eqs. (2) and (3)] can help to disentangle the simulated changes in NetCRF in the extratropics and to assign them to either dynamical changes, represented by changes in WCB locations and frequencies, or microphysical changes, as represented by the WCB effect. A first assessment of this partitioning in the present climate has been presented in this study, whereas the investigation of the link between WCBs and CRF in a future climate is subject of ongoing work.

Acknowledgments. I am grateful to Heini Wernli (ETH Zurich) for highly valuable discussions and comments on the results and on the manuscript. Many thanks also to Maxi Boettcher, Elisa Spreitzer, Michael Sprenger, and Lukas Papritz for taking time to discuss the results and to three anonymous reviewers for their helpful and inspiring comments which helped a lot to improve this manuscript. The CERES data were obtained from the NASA Langley Research Center CERES ordering tool at http://ceres.larc.nasa.gov/.

\section{REFERENCES}

Barnes, E. A., and L. Polvani, 2013: Response of the midlatitude jets, and of their variability, to increased greenhouse gases in the CMIP5 models. J. Climate, 26, 7117-7135, https://doi.org/ 10.1175/JCLI-D-12-00536.1.

Bender, F. A.-M., V. Ramanathan, and G. Tselioudis, 2012: Changes in extratropical storm track cloudiness 1983-2008: Observational support for a poleward shift. Climate Dyn., 38, 2037-2053, https://doi.org/10.1007/s00382-011-1065-6.

Binder, H., M. Boettcher, H. Joos, and H. Wernli, 2016: The role of warm conveyor belts for the intensification of extratropical cyclones in Northern Hemisphere winter. J. Atmos. Sci., 73, 3997-4020, https://doi.org/10.1175/JAS-D-15-0302.1. 
Bony, S., and Coauthors, 2015: Clouds, circulation and climate sensitivity. Nat. Geosci., 8, 261, https://doi.org/10.1038/ngeo2398.

Boucher, O., and Coauthors, 2013: Clouds and aerosols. Climate Change 2013: The Physical Science Basis, T. F. Stocker et al., Eds., Cambridge University Press, 571-657.

Browning, K. A., 1986: Conceptual models of precipitation systems. Wea. Forecasting, 1, 23-41, https://doi.org/10.1175/15200434(1986)001<0023:CMOPS > 2.0.CO;2.

Caldwell, P. M., M. D. Zelinka, K. E. Taylor, and K. Marvel, 2016: Quantifying the sources of intermodel spread in equilibrium climate sensitivity. J. Climate, 29, 513-524, https://doi.org/ 10.1175/JCLI-D-15-0352.1.

Ceppi, P., and D. L. Hartmann, 2015: Connections between clouds, radiation, and midlatitude dynamics: A review. Curr. Climate Change Rep., 1, 94-102, https://doi.org/10.1007/s40641-015-0010-x. - - - and M. J. Webb, 2016: Mechanisms of the negative shortwave cloud feedback in middle to high latitudes. J. Climate, 29, 139-157, https://doi.org/10.1175/JCLI-D-15-0327.1.

CERES Science Team, 2017: SYN1deg-3Hour Ed4A. NASA Atmospheric Science Data Center (ASDC), accessed 27 November 2017, https://doi.org/10.5067/Terra+Aqua/ CERES/SYN1deg-3HOUR_L3.004A.

Dee, D. P., and Coauthors, 2011: The ERA-Interim reanalysis: Configuration and performance of the data assimilations system. Quart. J. Roy. Meteor. Soc., 137, 553-597, https://doi.org/10.1002/qj.828.

Eastman, R., and S. G. Warren, 2013: A 39-yr survey of cloud changes from land stations worldwide 1971-2009: Long-term trends, relation to aerosols, and expansion of the tropical belt. J. Climate, 26, 1286-1303, https://doi.org/10.1175/JCLI-D-12-00280.1.

Field, P. R., A. Bodas-Salcedo, and M. E. Brooks, 2011: Using model analysis and satellite data to assess cloud and precipitation in midlatitude cyclones. Quart. J. Roy. Meteor. Soc., 137, 1501-1515, https://doi.org/10.1002/qj.858.

Govekar, P. D., C. Jakob, M. J. Reeder, and J. Haynes, 2011: The three-dimensional distribution of clouds around Southern Hemisphere extratropical cyclones. Geophys. Res. Lett., 38, L21805, https://doi.org/10.1029/2011GL049091.

Grise, K. M., L. M. Polvani, G. Tselioudis, Y. Wu, and M. D. Zelinka, 2013: The ozone hole indirect effect: Cloud-radiative anomalies accompanying the poleward shift of the eddydriven jet in the Southern Hemisphere. Geophys. Res. Lett., 40, 3688-3692, https://doi.org/10.1002/GRL.50675.

Joos, H., and H. Wernli, 2012: Influence of microphysical processes on the potential vorticity development in a warm conveyor belt: A case-study with the limited-area model COSMO. Quart. J. Roy. Meteor. Soc., 138, 407-418, https://doi.org/10.1002/qj.934.

_ on a warm conveyor belt and the downstream flow evolution. Quart. J. Roy. Meteor. Soc., 142, 2727-2739, https://doi.org/ 10.1002/qj.2863.

Klein, S., and D. Hartmann, 1993: The seasonal cycle of low stratiform clouds. J. Climate, 6, 1587-1606, https://doi.org/ 10.1175/1520-0442(1993)006<1587:TSCOLS $>2.0$. CO;2.

Kodama, C., S. Iga, and M. Satoh, 2014: Impact of the sea surface temperature rise on storm-track clouds in global nonhydrostatic aqua planet simulations. Geophys. Res. Lett., $\mathbf{4 1}$, 3545-3552, https://doi.org/10.1002/2014GL059972.

Madonna, E., H. Wernli, H. Joos, and O. Martius, 2014: Warm conveyor belts in the ERA-Interim dataset (1979-2010). Part I: Climatology and potential vorticity evolution. J. Climate, 27, 3-26, https://doi.org/10.1175/JCLI-D-12-00720.1.

McCoy, D. T., and Coauthors, 2018: Cloud feedbacks in extratropical cyclones: Insight from long-term satellite data and high-resolution global simulations. Atmos. Chem. Phys. Discuss., 2018, 1-44, https://doi.org/10.5194/acp-2018-785.

Naud, C. M., J. F. Booth, and A. D. Del Genio, 2014: Evaluation of ERA-Interim and MERRA cloudiness in the Southern Ocean. J. Climate, 27, 2109-2124, https://doi.org/10.1175/ JCLI-D-13-00432.1.

Pfahl, S., E. Madonna, M. Boettcher, H. Joos, and H. Wernli, 2014: Warm conveyor belts in the ERA-Interim dataset (19792010). Part II: Moisture origin and relevance for precipitation. J. Climate, 27, 27-40, https://doi.org/10.1175/JCLI-D-1300223.1.

Ramanathan, V., R. D. Cess, E. F. Harrison, P. Minnis, B. Barkstrom, E. Ahmad, and D. Hartmann, 1989: Cloudradiative forcing and climate: Results from the Earth Radiation Budget Experiment. Science, 243, 57-63, https:// doi.org/10.1126/science.243.4887.57.

Shaw, T. A., and Coauthors, 2016: Storm track processes and the opposing influences of climate change. Nat. Geosci., 9, 656664, https://doi.org/10.1038/NGEO2783.

Shepherd, T. G., 2014: Atmospheric circulation as a source of uncertainty in climate change projections. Nat. Geosci., 7, 703708, https://doi.org/10.1038/NGEO2253.

Sprenger, M., and H. Wernli, 2015: The LAGRANTO Lagrangian analysis tool-Version 2.0. Geosci. Model Dev., 8, 2569-2586, https://doi.org/10.5194/gmd-8-2569-2015.

Stengel, M., C. Schlundt, S. Stapelberg, O. Sus, S. Eliasson, U. Willen, and J. F. Meirink, 2018: Comparing ERA-Interim clouds with satellite observations using a simplified satellite simulator. Atmos. Chem. Phys., 18, 17 601-17 614, https:// doi.org/10.5194/acp-18-17601-2018.

Stewart, R. E., K. K. Szeto, R. F. Reinking, S. A. Clough, and S. P. Ballard, 1998: Midlatitude cyclonic cloud systems and their features affecting large scales and climate. Rev. Geophys., 36, 245-273, https://doi.org/10.1029/97RG03573.

Tselioudis, G., and W. B. Rossow, 2006: Climate feedback implied by observed radiation and precipitation changes with midlatitude storm strength and frequency. Geophys. Res. Lett., 33, L02704, https://doi.org/10.1029/2005G1024513.

Vial, J., J.-L. Dufresne, and S. Bony, 2013: On the interpretation of inter-model spread in CMIP5 climate sensitivity estimates. Climate Dyn., 41, 3339-3362, https://doi.org/10.1007/s00382013-1725-9.

Wernli, H., and H. C. Davies, 1997: A Lagrangian-based analysis of extratropical cyclones. I: The method and some applications. Quart. J. Roy. Meteor. Soc., 123, 467-489, https://doi.org/ 10.1002/qj.49712353811.

, and C. Schwierz, 2006: Surface cyclones in the ERA-40 dataset (1958-2001). Part I: Novel identification method and global climatology. J. Atmos. Sci., 63, 2486-2507, https:// doi.org/10.1175/JAS3766.1.

Wielicki, B. A., B. R. Barkstrom, E. F. Harrison, R. B. Lee III, G. L. Smith, and J. E. Cooper, 1996: Clouds and the Earth's Radiant Energy System (CERES): An Earth observing system experiment. Bull. Amer. Meteor. Soc., 77, 853-868, https://doi.org/ 10.1175/1520-0477(1996)077<0853:CATERE > 2.0.CO;2.

Wylie, D. P., and W. P. Menzel, 1989: Two years of cloud cover statistics using VAS. J. Climate, 2, 380-392, https://doi.org/ 10.1175/1520-0442(1989)002<0380:TYOCCS >2.0.CO;2.

Zelinka, M. D., S. A. Klein, K. E. Taylor, T. Andrews, M. J. Webb, J. M. Gregory, and P. M. Forster, 2013: Contributions of different cloud types to feedbacks and rapid adjustments in CMIP5. J. Climate, 26, 5007-5027, https://doi.org/10.1175/ JCLI-D-12-00555.1. 